\title{
ResearchOnline@JCU
}

This is the author-created version of the following work:

Tulloch, Vivitskaia, Pirotta, Vanessa, Grech, Alana, Crocetti, Susan, Double, Michael, How, Jason, Kemper, Catherine, Meager, Justin, Palmer, Carol, Peddemors, Victor, Waples, Kelly, Watson, Mandy, and Harcourt, Robert (2020) Long-term trends and a risk analysis of cetacean entanglements and bycatch in fisheries gear in Australian waters. Biodiversity and Conservation, 29 pp. 251282.

Access to this file is available from:

https://researchonline.jcu.edu.au/58956/

(C) Springer Nature B.V. 2019. In accordance with publisher's policies, the Author Accepted Manuscript of this publication is available Open Access from ResearchOnline@JCU.

Please refer to the original source for the final version of this work: https://doi.org/10.1007/s10531\%2D019\%2D01881\%2Dx 


\section{Biodiversity and Conservation \\ Long-term trends and a risk analysis of cetacean entanglements and bycatch in fisheries gear in Australian waters \\ --Manuscript Draft--}

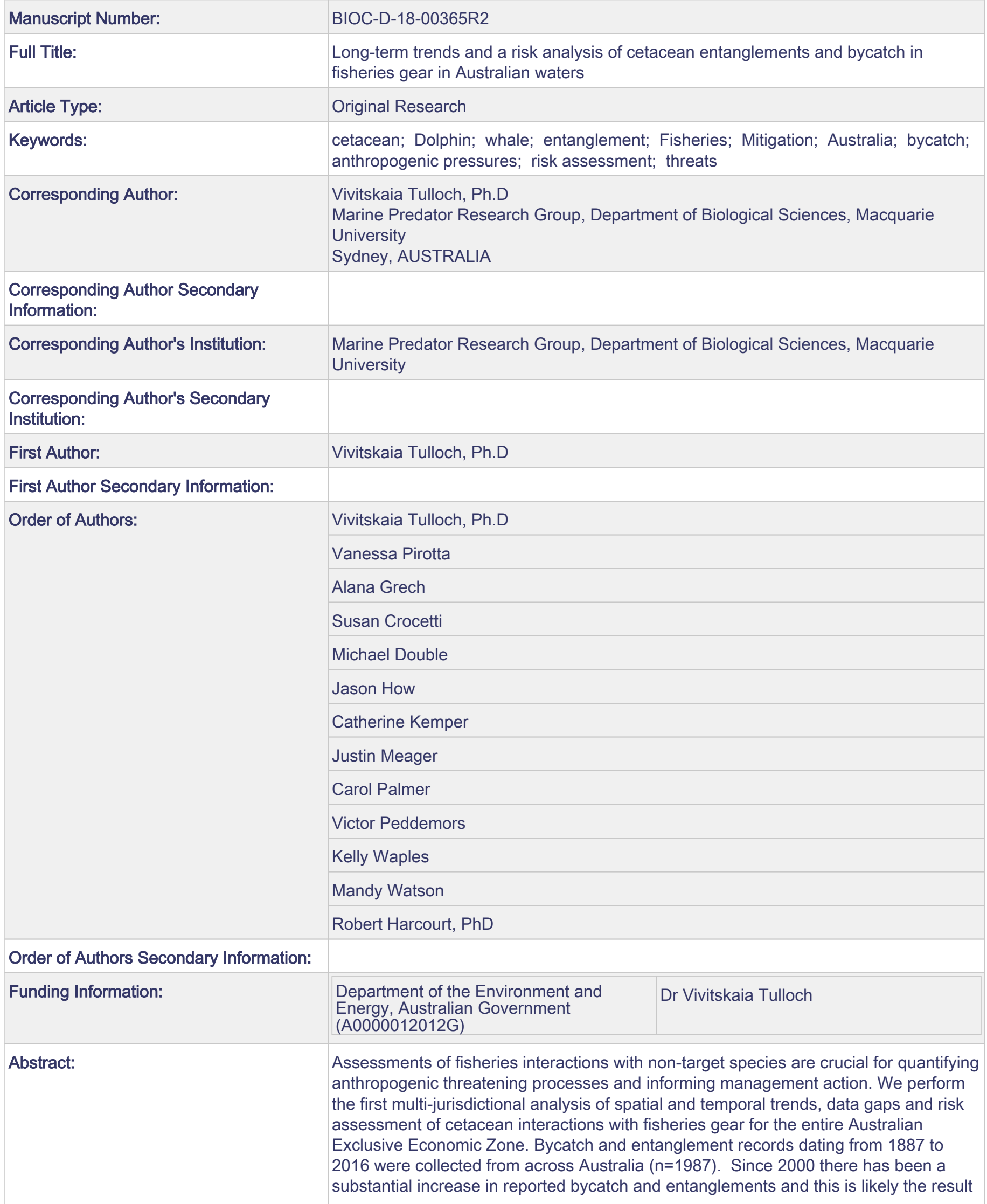


Response to Reviewers:

of improved monitoring or recording by some jurisdictions and fisheries as well as changing fishing effort, combined with continuing recovery of baleen whale populations after cessation of commercial whaling. A minimum of 27 cetacean species were recorded entangled, with over $30 \%$ of records involving interactions with threatened, vulnerable or endangered species. Three times the number of dolphins and toothed whales were recorded entangled compared to baleen whales. Inshore dolphins were assessed as most vulnerable to population decline as a result of entanglements, though humpback whales, common bottlenose dolphins, and short-beaked common dolphins were the most frequently caught. Only one-quarter of animals were reported to have survived entanglement, either through intervention or self-release from fishing gear. Spatial mapping of the records highlighted entanglement hotspots along the east and west coast of the continent, regions where high human population density, high fishing effort, and high density of migrating humpback whales all occur, augmented by high captures of dolphins in shark control gear along the east coast. Areas of few entanglements were more remote, highlighting substantial bias in entanglement reporting. Our gap analysis identified discrepancies in data quality and recording consistency both within and between jurisdictions. Disparities in the types of fisheries data provided for the analysis by different state agencies limited our ability to compile bycatch data in a representative and systematic way. This research highlights the need for improved standardised data recording and reporting by all agencies, and compulsory sharing of detailed fisheries interaction and effort data, as this would increase the value of entanglement and bycatch data as a conservation and management tool.

Dear Editor,

We have made all the required changes to the manuscript, detailed responses are below to the four minor edits.

Response to reviewers:

Line 40. Suggest 'Since 2000 there has been a substantial increase in reported bycatch and entanglements' to be consistent with lines 454-457

Response: Agreed, we have made the suggested change.

Line 283 'underestimate the true spatial distribution of interactions with active fisheries gear at a regional scale'. I don't fully understand this sentence and what the underestimate refers to. Is it the spatial extent or the number of interactions (or both)? Response: We have changed the text to clarify as follows: "These heat maps may underestimate the true spatial extent and number of interactions with active fisheries gear within coastal state waters, but can be considered a good representation of offshore interactions with federal fisheries that cross multiple jurisdictions"

Line 289 Suggest 'To evaluate spatial bias in reports of cetacean interactions, particularly from opportunistic reports by the public'

Response: Agreed.

Line 760 Suggest 'The most effective methods of reducing cetacean interactions with fishing gear'

Response: Agreed, we have made the suggested change. 
Click here to view linked References

1 Long-term trends and a risk analysis of cetacean entanglements and bycatch in fisheries gear

2 in Australian waters

4 Vivitskaia Tulloch ${ }^{1,2}$, Vanessa Pirotta ${ }^{1}$, Alana Grech $^{3,4}$, Susan Crocetti ${ }^{5}$, Michael Double ${ }^{6}$, Jason

5 How $^{7}$, Catherine Kemper ${ }^{8}$, Justin Meager ${ }^{9}$, Carol Palmer ${ }^{10}$, Victor Peddemors ${ }^{11}$, Kelly Waples ${ }^{12}$,

6 Mandy Watson $^{13}$, Robert Harcourt ${ }^{1}$

1. Marine Predator Research Group, Department of Biological Sciences, Macquarie University, Sydney, NSW, Australia

2. Australian Rivers Institute, Griffith University, Nathan, NSW, Australia

3. Department of Environmental Sciences, Macquarie University, Sydney, NSW, Australia

4. ARC Centre of Excellence for Coral Reef Studies, James Cook University, Townsville, Queensland, Australia

5. Department of Primary Industries, Parks, Water and Environment, Hobart, Tasmania, Australia

6. Biodiversity and Wildlife Unit, NSW National Parks and Wildlife Service, Office of Environment and Heritage, Australia

7. Australian Marine Mammal Centre Australian Antarctic Division 203 Channel Hwy, Kingston, Tasmania, Australia

8. Department of Primary Industries and Regional Development, Western Australia, Australia

9. South Australian Museum, North Terrace, Adelaide, SA 5000 Australia

10. Queensland Department of Environment and Science, GPO Box 2454, Dutton Park, Qld 4001, Australia

11. Marine Ecosystems, Flora and Fauna Division, Department of Environment and Natural Resources, Palmerston, Northern Territory, Australia

12. New South Wales Department of Industries, Mosman, New South Wales, Australia.

13. Department of Biodiversity, Conservation and Attractions, Western Australia, Australia

14. Department of Environment, Land, Water and Planning, Victoria, Australia

Corresponding author: 
v.tulloch@griffith.edu.au

ORCID ID: 0000-0002-7673-3716

\section{Abstract}

Assessments of fisheries interactions with non-target species are crucial for quantifying anthropogenic threatening processes and informing management action. We perform the first multijurisdictional analysis of spatial and temporal trends, data gaps and risk assessment of cetacean interactions with fisheries gear for the entire Australian Exclusive Economic Zone. Bycatch and entanglement records dating from 1887 to 2016 were collected from across Australia (n=1987). Since 2000 there has been a substantial increase in reported bycatch and entanglements and this is likely the result of improved monitoring or recording by some jurisdictions and fisheries as well as changing fishing effort, combined with continuing recovery of baleen whale populations after cessation of commercial whaling. A minimum of 27 cetacean species were recorded entangled, with over $30 \%$ of records involving interactions with threatened, vulnerable or endangered species. Three times the number of dolphins and toothed whales were recorded entangled compared to baleen whales. Inshore dolphins were assessed as most vulnerable to population decline as a result of entanglements, though humpback whales, common bottlenose dolphins, and short-beaked common dolphins were the most frequently caught. Only one-quarter of animals were reported to have survived entanglement, either through intervention or self-release from fishing gear. Spatial mapping of the records highlighted entanglement hotspots along the east and west coast of the continent, regions where high human population density, high fishing effort, and high density of migrating humpback whales all occur, augmented by high captures of dolphins in shark control gear along the east coast. Areas of few entanglements were more remote, highlighting substantial bias in entanglement reporting. Our gap analysis identified discrepancies in data quality and recording consistency both within and between jurisdictions. Disparities in the types of fisheries data provided for the analysis by different state agencies limited our ability to compile bycatch data in a representative and systematic way. This research highlights the need for improved standardised data recording and reporting by all agencies, and compulsory sharing of detailed fisheries interaction and effort data, as this would increase the value of entanglement and bycatch data as a conservation and management tool. anthropogenic pressures, risk assessment 
Bycatch and entanglement in fisheries gear are recognized as the most significant threat to the survival of cetacean species and populations globally (IWC 2010; Read 2008; Taylor et al. 2017). Expansion of both global fisheries and human populations in the past century has increased the presence of fishing gear in dolphin and whale habitat (Myers and Worm 2003), increasing the risk of interactions with fisheries gear (Cassoff et al. 2011; Pauly 2009). Our understanding of the scale and scope of the problem in many regions is impeded by the far-ranging distributions and crossjurisdictional movements of many whales and dolphins, which makes assessments especially difficult (Davidson et al. 2012; Schipper et al. 2008). Evaluation of long-term records of cetacean strandings and interactions with fisheries gear across large spatial scales is crucial to understand trends in capture and mortality due to human-use of marine environments (Byrd et al. 2014; Knowlton et al. 2012) and to help inform conservation actions (Groom and Coughran 2012). However, imperfect information on the status and demography of many whale and dolphin populations (Davidson et al. 2012; Schipper et al. 2008), and uncertainties in the effects of both historical and future pressures on species and populations (Clapham et al. 1999), challenges effective conservation.

Records of cetacean interactions with fisheries gear can be broadly separated into two different types - systematic reporting, such as commercial fisheries bycatch, and incidental/opportunistic reports. Fisheries bycatch typically refers to the fatal capture of non-target species in active commercial fishing gear (IWC 2016). For many years, international and domestic legislation have recognised the need to manage fisheries and potential negative impacts of bycatch on non-target species according to ecologically sustainable development principles (Fletcher et al. 2002). Bycatch is now systematically monitored and recorded by many commercial fisheries worldwide in recognition of its role in the depletion of many threatened species (Moore et al. 2009). Cetaceans also entangle in floating fisheries gear that may be displaced, or derelict, which we refer to as incidental entanglements, due to the fact that such incidents are typically not reported and recorded systematically. For instance, large cetaceans may move and displace active fishing gear, which then cannot be recorded using standard bycatch methods, making direct impacts more difficult to determine. Such displaced gear is considered to be 'inactive' from a fisheries perspective, although it may continue to catch or entangle both target and non-target marine animals (Scheld et al. 2016). Similarly, marine debris in the form of derelict fishing gear that has been abandoned, lost or discarded from commercial or recreational fisheries also poses a risk to many cetacean species (Baulch and Perry 2014), as well as other marine life including birds, sharks, turtles and other 
trends in interactions between cetaceans and fisheries that include records of both active and inactive gear, particularly at broad spatial scales relevant to the distribution of wide-ranging species. Globally, cetacean bycatch and gear entanglement has been identified as a leading cause of mortality in some species (Dayton et al. 1995; Kraus et al. 2005; Van Der Hoop et al. 2013) to the extent that it may be inhibiting population recovery (e.g. North Atlantic right whale (Eubalaena glacialis) (Knowlton et al. 2012), and is pushing some species towards extinction (e.g. the Vaquita (Phocoena sinus) (Taylor et al. 2017)). Population declines resulting from bycatch and entanglement have been documented (Lewison et al. 2004; Werner et al. 2015). Impacts on individuals can be severe; ranging from mortality, starvation due to impaired foraging through to laceration of large blood vessels, amputations and systemic infections that reduce the fitness of an individual animal and can eventually be fatal (Cassoff et al. 2011; Moore and Van der Hoop 2012; Wells et al. 2008). Our ability to understand both the intensity and effects of entanglements on cetaceans is hindered by inherent challenges in obtaining large-scale anthropogenic interaction data with far-ranging migratory pelagic species that can cross multiple jurisdiction boundaries, as well as in observing mobile or cryptic marine species. This is compounded by the difficulties in identifying the location and source of inactive fishing gear relative to where an interaction may occur (Reisser et al. 2013). Furthermore, species interact with multiple fisheries and multiple gears, but the demographic impacts of cumulative bycatch mortality are poorly understood (Moore et al. 2009), and our ability to detect population declines given current survey levels remains low (Taylor et al. 2007). In addition to these challenges, agencies collecting entanglement data may operate at different temporal or spatial scales, with different objectives ranging from animal welfare and wildlife conservation, to human-related activities and fisheries management. Further compounding these issues, and in contrast to the more systematic recording of bycatch, the comprehensiveness and accuracy of incidental entanglement records is largely dependent on opportunistic sightings by the public and/or strandings programs. The breadth and type of information collected can therefore vary considerably. Collation, evaluation and dissemination of accurate and comprehensive cetacean interaction data at multi-jurisdictional scales is crucial if we are to identify where points of vulnerability for far-ranging cetaceans exist, and so enable decision-makers to target potential mitigation actions towards areas, fisheries or specific gears.

Australia provides a unique opportunity to assess multi-jurisdictional fisheries impacts at a broad spatial scale because it is comprised of six states and two mainland territories and is the only country that spans an entire continent. Furthermore, Australia's Exclusive Economic Zone of 8.2 million $\mathrm{km}^{2}$ supports a large number of cetaceans, including resident dolphin species, two species of endemic tropical dolphins, and seasonal visitors such as baleen whales that travel along the east, west, and southern coastlines during their annual migration from the Southern Ocean to breeding 
and calving areas (Harcourt et al. 2014). Many whale species were pushed to the brink of extinction by historical commercial whaling in the $20^{\text {th }}$ century (Clapham 2002; Tønnessen and Johnsen 1982; Tulloch et al. 2017) including populations of humpback (Megaptera novaeangliae) and southern right whales (Eubalaena australis) that utilise Australian waters. As such, the waters around Australia are important for cetacean conservation. Under the Australian Environment Protection and Biodiversity Conservation Act 1999 (EPBC Act), all cetaceans in Australian waters are protected, with commercial fishers required to report any action that results in the death or injury of any cetacean species. Previous studies of incidental cetacean entanglements in fisheries gear have been conducted for over half of Australia's jurisdictions (e.g. Chatto and Warneke 2000 (Northern Territory [NT]); Groom and Coughran 2012 (Western Australia [WA]); Lloyd and Ross 2015 (New South Wales [NSW]); Reid and Krogh 1992 (NSW); Segawa and Kemper 2015 (South Australia [SA])). Although one study evaluated historical human interactions with southern right whales (Kemper et al. 2008), no national or large-scale analysis of incidental entanglements for cetaceans exists for Australia, despite the typically cross-jurisdictional geographic range of many cetacean species and fisheries. National Progress Reports describing anthropogenic impacts and sightings are submitted to the International Whaling Commission (IWC) by some member countries, including Australia, and contain information on entanglements across Australia, but lack of detail in the summaries prevents quantitative spatial or temporal analysis. Globally, numerous small-scale, single-gear, or single species assessments of whale or dolphin entanglements have been conducted in recent years (e.g. Knowlton et al. 2012; Slooten et al. 2000). Reviews of baleen whale entanglements are becoming more common, particularly for North America (e.g. Johnson et al. 2005), where summaries of baleen whale opportunistic entanglement records are now provided annually (NOAA 2016), and historical reviews of cetacean strandings exist for numbers of countries including England (Kirkwood et al. 1997) and the Canadian west coast (Guenther et al. 1995; e.g. Guenther et al. 1993). Regular assessments of commercial fisheries bycatch of cetaceans are also now conducted in many regions of the world (e.g. ICES 2017; National Marine Fisheries Service 2016), as well as regional stock assessments for marine mammals (e.g. Waring et al. 2013), though assessments of the magnitude of fisheries interactions with cetacean species in such reports are often couched in terms of high uncertainty. Many of these assessments derive from the grey literature as technical reports. Surprisingly, published studies evaluating spatio-temporal trends in entanglements and bycatch of both dolphins and whales at a national level that combine long-term opportunistic and systematic records, remain scarce.

\section{Aims and objectives:}


This is the first study to assess cetacean interactions in fisheries gear at a national scale, for the entire Australian EEZ. We collate all available data on entanglements and bycatch of cetaceans across Australia into one national database, and examine long-term trends in interaction rates, causes, and impacted species. We compare the species composition and mortality rates of cetacean entanglements in fishing gear across jurisdictions to investigate differences in fishing gear selectivity for catching baleen whales or dolphins. We undertake a risk assessment using the entanglement data to understand possible conservation implications of fisheries interactions for cetacean species historically entangled in gear in Australian waters. We evaluate intervention success across jurisdictions to assess whether disentanglement reduces overall mortality of cetaceans. Finally, we use heat maps of entanglement data to quantify the historical spatial location and intensity of cetacean interactions with fisheries gear, and to assess dispersal patterns at a national scale.

\section{Methods}

\section{Study area and species}

182 The Australian coastline extends for more than 30,000 kilometres (Fig. 1). Forty-five species of 183 cetacean (whales, dolphins and porpoises) are found in Australian waters including 9 baleen whales 184 (Mysticetes), and 36 toothed whales (Odontocetes) including species of beaked whales, sperm 185 whales, killer whales, dolphins and one porpoise, and all are protected under state and/or federal 186 legislation. Five baleen whale species are currently listed as nationally threatened under the 187 Australian EPBC Act including the endangered blue whale (Balaenoptera musculus) and southern 188 right whale (Table 1). The seasonal presence of some cetacean species in Australian waters varies 189 depending on migratory routes (Bryden et al. 1998). At least 11 species or sub-populations are 190 currently on the EPBC Act migratory species list, as per the Convention on the Conservation of 191 Migratory Species of Wild Animals (the Bonn Convention), including humpback and southern right 192 whales, and Australian snubfin (Orcaella heinsohni), Australian humpback (Sousa sahulensis) and 193 the Arafura/Timor Sea bottlenose dolphin (Tursiops aduncus, Table 1). Some species are 194 considered to be data deficient nationally but threatened under state legislation, such as the 195 Australian humpback dolphin and the Australian snubfin dolphin, which are listed as vulnerable in 196 the State of Queensland (Nature Conservation Act 1992 [Qld]), and are now also listed as 197 vulnerable by the IUCN Red List (Table 1).

198 Australia's commercial fisheries are governed by a total of eight jurisdictions (the Commonwealth 199 [Australian], six states and the Northern Territory), with specific regimes for management, research, 200 reporting and environmental protection within each jurisdiction. Although state/territory laws 
generally apply to coastal waters (up to three nautical miles seaward of the territorial sea baseline) and Commonwealth laws apply from those waters out to the limit of the Australian fishing zone (200 $\mathrm{nm}$ from the baseline), there are also 59 offshore settlement arrangements for managing crossjurisdictional stocks (Productivity Commission 2016). Local agencies maintain records on strandings, bycatch and incidental cetacean entanglements under their respective jurisdictions, and the Commonwealth Government records non-target species interactions in their fisheries extending to the outer limits of the Australian Fishing Zone (from 3 to 200nm offshore).

\section{Data collation}

210 We identified two types of interaction data for collation - "incidental entanglement" records from 211 agencies involved in monitoring and/or protection of cetaceans, and "systematic" records, which 212 refers to data that have been systematically recorded for a period of time by one agency (i.e. 213 fisheries bycatch and shark control program data). We made requests for cetacean incidental 214 entanglement data to applicable state and Commonwealth (Australian) agencies (Table S1), 215 including environment departments and parks and wildlife services, museums, aquaria, zoos, local 216 councils, and non-government agencies. National and international cetacean interaction database 217 records, and shark control program bycatch for both the Queensland Shark Control Program and the 218 NSW Bather Protection Program were also obtained (Table S1). Requests were made to fisheries 219 management agencies for spatially-referenced bycatch records and fisheries effort for all commercial fisheries known to interact with cetaceans. This data is typically recorded in fisheries logbooks, and by observers, and requirements for recording and reporting vary depending on the state and fishery. Many requests for bycatch and fisheries effort data were either ignored or refused

223 largely on the basis of confidentiality, or a lack of spatial information recorded for interactions 224 (Table S1).

225 A national entanglement and bycatch database was created containing 13 separate attributes for 226 each incident to assist comparison. Entanglement events involving more than one individual were 227 disaggregated into individual records for each animal. Any duplicate records were identified and removed. We assigned each record the following attributes: 1) species name (including suborder, family, genus and species where possible); 2) lowest possible taxon identification (i.e. species, genus, family or suborder); 3) gear type (e.g. line, net, trap, etc); 4) fishery involved (if identified); 5) date of entanglement; 6) location of reported entanglement (including latitude and longitude if provided); 7) condition of animal (alive, dead, unknown); 8) management intervention (if any, see Supplementary Methods); 9) final outcome of entanglement (alive still entangled, alive disentangled, dead, unknown); 10) source of data (i.e. agency responsible for collection and 
provision); 11) record type (systematic - bycatch, incidental, systematic - shark control, national/international database, and unknown), 12) gear status (bycatch - active gear, incidental attributed to active gear, floating - attributed to active gear, floating - possible derelict, unknown), and 13) notes on incident and any intervention. All jurisdictions provided incidental entanglement data, albeit for different time scales, and comprehensiveness of information supplied varied (Table S1, Supplementary methods). Due to disparate initial data supplied from each jurisdiction, and uncertainties in exact identification of gear to fishery source, we aggregated records by broader gear types: aquaculture, line, net, purse seine, trawl, trap, shark net, shark drumline, and unidentified (Supplementary Methods). Where there was no information on the fate of the individual animal, the initial status at the time the entanglement was reported was retained. If there were no data on management actions, the record was attributed "alive still entangled". If the initial status was unknown, or if concern was expressed on the outcome of the interaction, the final fate was assigned as "unknown", as were animals considered to be in poor condition. These assumptions are conservative and likely over-estimate the number of animals left alive after entanglement, given substantial evidence that a significant proportion of large baleen whale entanglements are ultimately fatal if gear is not removed (Cassoff et al. 2011; Knowlton et al. 2012).

We performed statistics on all attributes for all data combined, then by jurisdiction, and by species. Given differences in phenology and demography between cetacean species, we compared entanglement records of baleen whales (Mysticeti) and toothed whales and dolphins (Odontoceti), to see if trends differed between species. We evaluated differences in number of bycatch versus incidental records, and estimated the relative contribution of derelict or discarded gear compared with interactions with active fisheries gear based on the "gear status" category. The vast majority of datasets did not have associated measures of recording and reporting effort, therefore comprehensive bias corrections could not be applied to account for variable effort within and between jurisdictions. We performed separate statistics on a subset of records from 2000 onwards to account for some of the temporal and spatial bias in the records, as these were the years for which data was available from every jurisdiction, due in part to implementation of the EPBC Act in 1999 requiring reporting of cetacean-fisheries interactions.

\section{Analysis of spatial trends in cetacean interactions with fisheries gear}

Due to large variation in the number of records and in the spatial and temporal resolutions of the individual datasets, as well as the far-ranging and mobile nature of cetacean species, we choose to analyse data in 30 minute grid cells (3,178 units) at the level of months pooled across years. We digitized interaction records where latitude and longitude were provided $(n=1,556)$ by importing the 
coordinates as points into the geographic information system (GIS) software ArcGIS 10.3.1, using the Geocentric Datum of Australia 1994 Coordinate System. We created heat maps of entanglement records by summing together all points within each grid square. Heat maps were also created identifying species richness of entanglements spatially, by summing together the number of different species reported entangled in each grid, as well as where the highest numbers of fatal incidents have occurred across Australia. We also derived a heat map of numbers of entanglements for species listed in any threatened or migratory categories under the EPBC Act or IUCN Red List criteria, and finally derived a difference map where we subtracted the total number of Mysticeti interactions per grid from the total Odontoceti interactions, identifying areas of higher entanglements with dolphins and toothed whales versus baleen whales. We defined coldspots as areas where there were no records of entanglements overall, or $<1$ before 2000 and none since.

All records with spatial information were included in the heat maps, which included incidental records and Commonwealth fisheries bycatch. We reduced spatial bias in discrepancies across data provided by each state by excluding bycatch records from state-based fisheries, and used only data from 1990 onwards. These heat maps may underestimate the true spatial extent and number of interactions with active fisheries gear within coastal state waters, but can be considered a good representation of offshore interactions with federal fisheries that cross multiple jurisdictions. Further, these heat maps do not identify entanglement risk, which would require information on fishing intensity across Australia, as these data were not provided by most commercial fisheries agencies despite being requested, but instead highlight regions where high numbers of entanglement have historically been reported.

To evaluate spatial bias in reports of cetacean interactions, particularly from opportunistic reports 291 by the public, we obtained data on human population density and "remoteness" across Australia 292 from the Australian Bureau of Statistics (ABS 2011), to compare with the location of reported 293 entanglement or bycatch hotspots, hypothesizing that areas of high numbers of reports may correspond with coastal areas of high human population density (Lloyd and Ross 2015). The ABS remoteness data was developed originally as the Accessibility/Remoteness Index of Australia (ARIA) by the Hugo Centre (2014), and classifies Australia into regions that share common characteristics of geographic remoteness. We assigned each grid square a remoteness category based on proximity to the nearest remoteness polygon, and used the residuals from a generalized 299 linear model (GLM) of the number of entanglements versus the remoteness category to generate a 300 'remoteness standardised' index for each grid cell. 
We evaluated species composition of entanglements by suborder, family, genus and species, and compared Mysticeti and Odontoceti data separately to examine differences between baleen and toothed cetacean interactions with fisheries. We then conducted a semi-quantitative risk assessment of entanglements by gear type and species, based on an established risk assessment framework used in recovery plans for other marine megafauna (e.g. turtles, Commonwealth of Australia 2017) to identify those species at highest risk of interactions with fisheries by broad gear type (Supplementary Methods). In a typical risk analysis, risk is ranked based on the likelihood of the threat occurring, and the consequences (Harwood 2000). In our risk assessment, we quantified the likelihood of exposure of each species to fishery gear types in Australian waters based on the proportion of historical entanglements, and the consequences of each threatening process on each species category based on the species mortality in each gear, weighted by their threatened status listing under the EPBC Act, state legislation or the IUCN (Supplementary Methods). We multiplied the likelihood by the consequences to get a relative risk metric for each species and gear type. We then used relevant literature to modify any risk categories that were zero (due to no reported records of entanglement), but where the literature or historic records suggested there was a chance of entanglement for that species category, and modified the consequences parameter based on the status and abundance of each species in Australian waters (Supplementary Methods).

\section{Analysis of temporal trends in cetacean interactions with fisheries gear}

Temporal trends of reported interactions were examined using a Gaussian generalised additive mixed-effect model (GAMM, hereafter "full model"). Collinearity of variables was assessed by calculating correlation coefficients. Given that several variables were highly correlated with each other, we included only one species level (suborder) and excluded source of data and gear status from the main-effect model to avoid multiple collinearity (Table S3). The following variables were included in the final model fitting: number of entanglements, year, suborder, gear, record type, and jurisdiction. Model fit was evaluated by residual diagnostics and the choice of the final model was guided by Akaike's Information Criterion (AIC), by fitting all covariates then simplifying to find the most parsimonious model based on the AIC (Table S3). GAMMs were fitted using the 'mgcv' (version 1.7-247, (Wood 2006)) of the R software environment (version 3.0.2, R Core Team, 2013). In the final model the relationship between entanglement rate and year was described by a nonlinear smoothing function, and a fixed effect was included for the data type (incidental entanglement or bycatch). We treated each jurisdiction as a random intercept to reduce the influence of bias from differences in reporting between jurisdictions by modelling the 'average' trend. We undertook a separate analysis for years $>2000$ to assess for model sensitivity to improved reporting effort. 
We also conducted linear regressions between the number of interactions by suborder and year and used the goodness-of-fit statistic $\left(\mathrm{r}^{2}\right)$ to provide an indication of the strength of the relationship. To account for some of the bias in the data, we performed a number of sensitivity tests. We modelled subsets of the data from 1990 to reduce the influence of bias from differences in reporting, and again from 2000, to also account for improved effort in recording post-implementation of the EPBC Act in 1999. We also compared models including and excluding bycatch records given the data discrepancies.

Standardised entanglement rates for each jurisdiction were derived by dividing the total number of incidental entanglement records for each jurisdiction by the number of years data was provided. We could not account for changes in monitoring effort by agencies over time both within and between jurisdictions, as this information was not available, and instead calculated a relative measure of reporting rates between regions over time. We compared this with a rate that also included bycatch records, with Commonwealth fisheries records assigned to the state region where the interaction occurred, to examine spatial trends in entanglement across Australia from both active and inactive gear. We repeated this for separate 10-year time periods (1986-1995, 1996-2005, 2006-2015) to examine temporal trends in reporting rate.

An additional GAMM model was used to assess the influence of fishing effort on temporal bycatch trends (hereafter "Commonwealth model"). Effort data (annual catch-per-unit-effort, CPUE) were provided by the Australian Fisheries Management Authority (AFMA) for those fisheries noted as having cetacean interactions: Commonwealth Trawl Sector of the Commonwealth Southern and Eastern Scalefish and Shark Fishery (SESSF), Gillnet Hook and Trap Sector of the SESSF, Northern Prawn Fishery, Small Pelagic Fishery, Western and Eastern Tuna and Billfish Fishery. We extracted the subset of Commonwealth fisheries bycatch records from the national entanglement dataset. Fisheries effort data were provided for the same time-series as interaction records (from 2000-2015), by gear type and fishery. We then modelled the temporal trend in CPUE using a GAMM with catch rates as the log-transformed response variable, a covariate for nominal fishing effort (log transformed), a random intercept for the fishery and a non-linear smoothing function for year.

\section{Analysis of mortality rates and intervention success}

To evaluate the success of disentanglement operations we performed analyses on data for which detailed management intervention information has been recorded. We calculated statistics on disentanglement success and failure and resulting fate of each animal. We then performed regressions on intervention rate versus mortality rate, at a national level, to see if changes in overall 
mortality could be explained by interventions alone. We obtained statistics by year, and as a summed total across all years. Because of the high uncertainty in the final fate of individual animals post-entanglement in fisheries gear, we conducted a sensitivity test on our analyses of intervention outcomes whereby we assumed all unreleased animals (left still entangled) died.

\section{Analysis of fisheries gear selectivity}

We evaluated differences in the selectivity of gear in catching Odontocetes or Mysticetes by comparing annual and overall catch rates in each gear type and examined how this varied spatially across Australia.

\section{Results}

We collated 1,987 records of cetacean incidental entanglements and bycatch throughout Australian waters (Table 1), dating from 1887 to 2016, from a range of state, federal and international sources (Supplementary Table S1). We collated 833 incidental records, and 1154 systematic records from fisheries bycatch and shark control programs $(n=497)$. Commonwealth bycatch data were provided by AFMA from $2000(n=339)$ and fisheries effort for the same time period. Some recent non-spatial bycatch summary data were obtained for two state jurisdictions ( $\mathrm{SA}=47$; WA=321). Spatial information was not included for 421 (21\% of total) records, therefore these were excluded from the geographical analyses.

Two-thirds of all records $(n=1271)$ could be attributed to bycatch in commercial fisheries (albeit the means of reporting varied between systematic records and incidental reports), and over $10 \%$ of floating entanglements $(n=213)$ reported incidentally could also be attributed to active fisheries or shark control gear. One quarter of incidental records could not be attributed to active gear in fisheries, and were assumed to be entanglements in derelict gear.

\section{Spatial trends in cetacean interactions with fisheries gear}

The major historical hotspots of reported interactions (>20 individual animals based on all incidental records with spatial information, shark control data, and Commonwealth fisheries bycatch only) were along the east coast of Australia, as well as smaller areas in the southern Spencer Gulf and Tasmanian coast and near the state capital Perth on the west coast (Fig. 1a). Historical coldspots in reported interactions were identified in the Gulf of Carpentaria and Cape York, the waters off the north-west coast, as well as the south-west coastline of the Great Australian 
Bight (Fig. 1a). By examining the proximity of entanglement hotspots to a remoteness index for Australia, we observed that areas of no records typically occurred adjacent to terrestrial areas classified in the most remote category (Figs. 1a,b). The remoteness model revealed a significant relationship between the location of major cities and entanglements $(F=4.0, p<0.001$; estimated degrees of freedom, edf $=5.5$ ), with a total of only 152 entanglements reported adjacent to the most remote regions of Australia. The standardized remoteness index map of residuals showed a relatively close fit for most regions (Fig. S1), although the model under-predicted values adjacent to capital cities along the east and west of Australia (Sydney, Perth). Jurisdictions with fewer records (particularly NT, TAS and VIC) also had more remote coastline than other states.

\section{Numbers of species recorded within each jurisdiction and accuracy of identification varied} considerably, with hotspots of listed species entanglements and bycatch along the east and west coast of Australia (NSW: n=165, Qld: n=156 and WA: n=162, Fig. 1c). Spatial differences were observed in the proportion of whales compared to dolphins entangled across Australia (Fig. 1d). Along the southern coastline, there were more incidents involving toothed whale and dolphin species, though Victoria reported mostly baleen whale incidental entanglements, and higher numbers of baleen whales were recorded along the west and east coasts (Fig. 1d).

Spatial aggregation by grid of all records resulting in death or where the animal was still entangled revealed hotspots of high mortality risk along the eastern Australian coast, where shark net density is high (Fig. S1, Green et al. 2009). The lower Spencer Gulf in South Australia also showed high numbers of dead or still entangled animals (Fig. 1e), with analysis showing these were mostly dolphin bycatch in Commonwealth fisheries.

\section{Species vulnerability and risk to fisheries gear interactions}

In total, 27 cetacean species were recorded in entanglements and bycatch (Table 1). Of the 1,987 total records, only 1,300 were identified to a species level (including 164 records of Tursiops spp.). Almost $30 \%$ of reported interactions $(n=586)$ involved listed threatened or migratory species as per the IUCN Red List and EPBC Act (9 species, Table 1). There were two recorded incidental entanglements for blue whales, and 28 for southern right whales, both listed as Endangered under the EPBC Act, as well as small numbers of Vulnerable snubfin $(n=27)$ or humpback dolphin $(n=$ 15) records largely in nets including those of shark control. Humpback whales $(n=368)$, shortbeaked common dolphins (Delphinus delphis, $\mathrm{n}=408$ ) and bottlenose dolphins (Tursiops spp., $\mathrm{n}=318$ ) together accounted for over half the total number of records identified down to species level. Records of unidentified species included at least 42 baleen whales, and more than 480 dolphins. Eight species were recorded only once, including the Antarctic minke (Balaenoptera 
bonaerensis), Bryde's whale (Balaenoptera edeni) and six toothed whales and dolphins, while another six species had five or fewer records over the entire time period (Table 1).

Overall, three times the number of toothed whales and dolphins have been reported entangled or caught in fisheries gear compared to baleen whales. The majority of bycatch and shark control interactions have involved toothed whales and dolphins, with only $10 \%(\mathrm{n}=110)$ involving baleen whales. In contrast, baleen whales have comprised two-thirds of all incidental entanglements records (excluding bycatch and shark control) over the last 15 years, although total numbers of incidental entanglements across all years are split almost 50-50 between baleen whales and toothed whales/dolphins.

Our retrospective risk assessment identified very high risk associated with interactions between net gear (including shark nets) and three dolphin species (humpback, Indo-Pacific bottlenose, and short-beaked common dolphins), due to high mortality risk in these gear (Table S3), with high risk categories also afforded to snubfin dolphin interaction with these gear types (Table 2). The highest risk to baleen whales assessed was for trap and net gear for interactions with southern right and humpback whales (Table 2).

\section{Temporal trends in cetacean interactions with fisheries gear}

Total reported annual cetacean interactions with fisheries gear have been increasing since reporting requirements for state agencies began (Fig. 2a). Numbers of reported commercial fisheries interactions reported since 2000 totaled 634, compared to 522 for the same time period for incidental entanglements, with reports for both increasing.

Regressions between the number of interactions and year identified greater increasing trends of dolphin and toothed whale interactions overall $\left(r^{2}=0.82\right)$ compared to baleen whales $\left(r^{2}=0.45\right.$, Fig. 2a). A strong positive relationship between number of records (both incidental and systematic) and year was shown in the initial full model $(\mathrm{F}=4.5, \mathrm{p}<0.001$; edf $=1.9)$, with large confidence intervals for pre $\sim 1990$ data due to few jurisdictions providing data before this year due to variable reporting requirements across the nation (Fig. S3a, Table S1). There was high uncertainty in full model predictions before 1980 (Fig. 2), driven by inconsistent reporting effort, insufficient state fishery data, and a lack of data prior to 1995 in the north (NT) and the most southern states (VIC and TAS) where annual counts have remained relatively low since reporting began (Fig. 3, Table S1). To reduce this uncertainty, we limited the time period of the model to post-1990, enabling better coverage of incidental data between jurisdictions. Increasing trends in the number of reported interactions in the best-fit model using data from 1990 (see Table S3) were again observed, with large increases since 2000 driven by the addition of fisheries bycatch records for some states $(\mathrm{F}=$ 
0.7, $\mathrm{p}<0.001$; edf $=2.3$, Fig. 2a). Comparison between the full model with a model that excluded

473 fisheries bycatch records also identified similar increasing trends between 1998 and $2011(\mathrm{~F}=7.8$,

$474 \mathrm{p}<0.001$; edf $=5.5$ ), with a decline from 2011 to 2015 (Fig. 2b), and further declines prior to 1997

475 from a peak in 1994 (Fig. 2b). The number of records for 2016 was lower than in previous years

476 due to not all data for the most recent years being processed yet, in particular Commonwealth

477 fisheries and shark control program records (see Table S1).

478 Examination of data for each region separately identified differences in long-term trends between

479 jurisdictions and disparate numbers of incidental and systematic records. The largest number of 480 records came from the north-east $(\mathrm{QLD}, \mathrm{n}=535)$ and west coast (WA, $\mathrm{n}=522)$, together comprising 481 over half of the records, followed by NSW and SA, which comprised $\sim 15 \%(\mathrm{n}=291)$ and $\sim 10 \%$ $482(\mathrm{n}=210)$ of all reported interactions respectively (Table 1). These states all reported increases in 483 interaction rate since 2005 compared to the previous 10 years (Fig. 3), largely due to the addition of 484 fisheries bycatch data (with the exception of NSW) and increases in Queensland shark control 485 interactions. Peaks in reported cetacean interactions occurred predominantly during the Austral winter, driven by peak baleen whale entanglement during July and August (Fig. 2c) corresponding with the coastal migration of humpback whales north to breeding grounds in the tropics. There were no clear monthly trends for dolphins and toothed whale interactions (Fig. 2c).

489 Approximately $17 \%$ of the total records were bycatch from Commonwealth fisheries. The best-fit 490 model for the subset of Commonwealth bycatch data showed a decline in entanglements between 4912000 and 2006, followed by a steep increase from 2010 to 2015 ( $F=0.7, p<0.001$; edf $=2.0$, Fig. $492 \mathrm{~S} 3 \mathrm{~b}$ ). Bycatch numbers differed significantly between the 5 fisheries tested ( $p$ values from $<0.001$ 493 to 0.22 ), though the relationship between log effort and bycatch number was highly significant ( $p$ 494 0.001). Note, although the Commonwealth data provided the highest quality fishery interaction 495 data, we used logbook records only, and excluded observer records as they are unreliable for 496 interaction numbers prior to 2008 (AFMA 2017). Earlier Commonwealth records are therefore 497 considered to be underestimates, as interactions recorded by observers can be much higher than 498 those reported in logbooks (Hamer et al. 2008).

499 We compared interaction rates at 10-yearly time periods for all data and a subset of the records 500 excluding commercial fisheries bycatch records, to remove bias from inconsistencies in fisheries 501 data provision across jurisdictions. Average interaction rates for data excluding commercial 502 fisheries bycatch over all the years were highest for the east coast (17/y for QLD and 11/y for 503 NSW), largely driven by high numbers of entanglements in Queensland shark control gear. Due to 504 intense monitoring of these programs over the years, these programs provide a realistic indication of 505 reporting effort and long-term change in catch rate across this region (Reid et al. 2011). Reporting of interactions excluding bycatch have increased since 1986 for most jurisdictions, with changes 
particularly evident in states along the east and west coasts (QLD, NSW and WA), where average reported interaction rates for the last 10 years have been high (25/yr, 15/yr and 11/yr respectively) (Fig. 3a).

\section{Mortality rates and intervention success}

512 Almost two-thirds $(\mathrm{n}=1133)$ of all cetacean interactions with fisheries gear have been fatal, mostly involving dolphin and toothed whale species $(n=1085)$, with only $9 \%$ of baleen whale records resulting in death $(n=46)$. If we assumed all unreleased animals died, $75 \%$ of interactions per year are fatal on average. The number of mortalities has increased overall in the past 10 years (Fig. 4a), but this reflects higher numbers of entanglement and bycatch records due to improved recording, because the overall proportion of lethal interactions has decreased. Approximately $80 \%$ of historical records prior to 2000 resulted in death, the majority of these delphinids ( $\mathrm{n}=252)$, compared to $<50 \%$ on average over the last 5 years (Fig. 4b).

The number of reported interventions has increased three-fold since 2000 (Figs. 4c, S3a). Linear regression of the proportion of reported fatal interactions with the intervention rate annually revealed disentanglement procedures may be reducing overall mortality rates for whales and dolphins $\left(r^{2}=0.22\right.$, Fig. $\left.4 c\right)$, however numbers of still entangled animals continue to increase, and ultimately this may also be fatal. The results of our sensitivity test assuming unreleased animals die, still suggested increased numbers of interventions could explain the reduced rate of mortality over time, but explanatory power was low $\left(r^{2}=0.10\right.$, Fig. $\left.S 4 b\right)$. Overall, changes in the proportion of successful disentanglements over the last 20 years have been slight, although several peaks in the number of successful disentanglements have occurred since 2000, including two years (2004 and 2016) where more than half the reported entanglements resulted in successful disentanglement (Fig. 4), whether through the work of rescue teams, or because the animals freed themselves. Reports across all agencies of baleen whales remaining entangled increased nine-fold between 2000 and

533 Of the 833 reported incidental entanglements (excluding bycatch and shark control), almost one534 third of animals remained entangled (Table 3), mostly large baleen whales $(n=241)$. Interventions for incidental entanglements have been recorded for 193 animals, of which almost $70 \%$ have resulted in successful disentanglement, compared with a small number of fatal or unknown outcomes (Table 3). One-quarter of interventions $(n=50)$ failed leaving the animal still entangled in fisheries gear. Reasons for failure included dangerous conditions, the animal evading disentanglement teams, or only partial disentanglement of gear. Almost all intervention failures 540 have involved baleen whales $(n=41)$. Only $6 \%$ of records noted animals had released themselves 
541 from fisheries gear (Table 3). There were no interventions for incidental entanglements recorded

542 before 1990.

543 Analysis of intervention success for the 1154 systematic records (commercial bycatch and shark

544 control) revealed disentanglement attempts were made for only $30 \%$ of records overall $(n=348)$, due

545 to the remaining interactions being fatal (Table 3). Over $90 \%$ of bycatch and shark control

546 interactions involved dolphins and toothed whales $(n=1014)$. Of those animals still alive after

547 entanglement, all but 2 humpback whales were successfully disentangled and released alive,

548 although reports of post-capture condition varied considerably between animals, ranging from

549 scarring and severe lacerations to amputated fins and tails. The annual proportion of bycatch and

550 shark control disentanglements has varied considerably over the last 15 years (0.2 - 0.6). Linear

551 regressions of mortality rates for commercial fisheries bycatch as a proportion of total

552 entanglements showed slightly increasing trends since $2000\left(r^{2}=0.26\right.$, Fig. S4a), whilst for the same

553 period decreasing trends in mortality rates as a proportion of total records were observed for shark

554 control programs $\left(r^{2}=0.23\right.$, Fig. S5b).

\section{Fisheries gear selectivity}

557 Most deaths occurred in nets, predominantly shark control nets $(n=356)$, with over one-quarter $(n=$

558 532) of all recorded entanglements from the shark control programs along the east coast of

559 Australia (QLD and NSW), and these involved predominantly delphinid species. Many mortalities

560 were also recorded in trawl nets $(n=220)$ and gillnets $(n=173)$. Baleen whales were more likely to

561 be entangled in traps (lobster, crab, octopus and fish) and ropes (Fig. 5a), whereas odontocete

562 interactions involved a much broader range of gear (Fig. 5b). Although approximately $40 \%(\mathrm{n}=233)$

563 of entangled threatened or migratory species survived the incident and were successfully released,

564 the same number were left entangled $(n=235)$, with at least 80 resulting in the animals' eventual

565 death. Type of gear involved was not provided for over one-quarter of records.

566 Geographically the types of gear involved in cetacean interactions have varied across Australia

567 (Fig. 6). Large numbers of records along the east coast of Australia were primarily due to

568 interactions with the two shark control programs, with other gear interactions relatively minor

569 compared with similar latitudes on the west coast where trawl and trap gear are the major forms of

570 interaction (Fig. 6). For southern Australia, gillnets and commercial purse seine nets were the main

571 gear responsible for bycatch and entanglements, although there have also been numbers of

572 interactions with aquaculture gear in Tasmania (Fig. 6). Trawl interactions were also frequent in the

573 south and north, principally involving dolphin mortalities (Fig. 5b). 


\section{Discussion}

576 This study is the first to present long-term trends in cetacean interactions with fisheries gear, and was achieved by collating and analysing entanglement data from numerous disparate sources, including commercial fisheries and incidental records from federal and state jurisdictions across the whole Australian continent. The almost 2,000 records involving at least 27 species of whales and dolphins in Australian waters highlights the pervasive, widespread nature of cetacean entanglements in fisheries gear. It also likely under-represents the magnitude of impact, as data required to monitor cetacean populations and understand fisheries-related impacts (e.g. population abundance estimates, fishing effort, spatial bycatch composition and entanglement rates to speciesspecific level) were either not provided by state agencies, or have not been consistently collected historically. Our spatio-temporal analyses provide important information on how cetaceans interact with active fisheries and derelict gear around Australia, as well as indicating where and when management particularly by fisheries may be having a positive impact. Despite historical data gaps, analyses of recent records that reflect improved recording effort highlighted that there are overall increasing trends in dolphin and whale interactions across Australian waters (Fig. 2). Ongoing mortality particularly of delphinids suggest that current management efforts have not been enough to mitigate fatalities of cetaceans in fisheries gear. This supports other observations around the globe of increasing whale entanglements, for example along the west coast of North America (NOAA 2016), and ongoing fatalities of dolphins in net gear globally (Atkins et al. 2016; Read et al. 2006). Importantly, we show that the risk of entangling in active gear around Australia greatly exceeds that of discarded and derelict gear, with almost three-quarters of records attributed to active fisheries, irrespective of the reporting method. By using a risk framework to evaluate historical entanglements and potential impacts on populations, we show even low levels of interaction may be a cause for concern for vulnerable species such as coastal dolphins and southern right whales, and this may have important implications for their conservation as well as ongoing management of fisheries in Australian waters.

601 A number of factors may be contributing to increasing entanglement trends, including biological 602 factors, changes in fishing effort, as well as an increase in implementation and enforcement of reporting by agencies and management authorities, compliance with regulations by fishers (Pikesley et al. 2012), and increasing public awareness of, and engagement in, reporting of cetacean entanglements and strandings. Biological factors affecting the location and number of fisheries may include spatial variability in species richness, the location of critical habitat and aggregating areas for cetaceans, such as breeding or feeding areas, and migratory corridors, and the distribution and abundance of cetacean populations. The most common species entangled historically (humpback whales, bottlenose dolphins, and short-beaked common dolphins) are also the most abundant 
cetacean species in Australian coastal waters (Noad et al. 2011; Ross 2006; Salgado Kent et al. 2012). Despite heavy depletion from whaling, most populations of migratory humpback whales have recovered strongly, with the east coast Australian population already 98\% recovered in 2015 (Jackson et al. 2015; Noad et al. 2016), and west coast Australian populations predicted to reach pre-whaling levels ( 45,000) by around 2020 (Salgado Kent et al. 2012). Increases in entanglement numbers given burgeoning whale populations are not unexpected (How et al. 2015), but as these populations are already large, the results of our risk assessment suggest entanglement at current rates is unlikely to have serious impacts at the population level (Table 2).

Few southern right whales have been reported entangled in Australia (Kemper et al. 2008), but the population estimate is low $(<4,000)$ due to slow recovery from $19^{\text {th }}$ century whaling (Carroll et al. 2011). In the North Atlantic, entanglements and vessel strike of the congeneric northern right whale are major limiting factors for recovery of this endangered species (Pace et al. 2017). For the Australian species, there is evidence for two distinct populations reflecting high site fidelity in the south-east and south-west, with the remnant south-east population particularly vulnerable based on current population estimates and rate of recovery (Carroll et al. 2015). The southern right whale thus may be particularly vulnerable to local threats such as entanglement (Table 2). Changes to the southern rock lobster trap fishery in SA, including opening the fishing season year round since 2017 (Linnane et al. 2017), have increased the number of gear and vessels in or near important calving grounds and migratory routes, and this may result in more right whale entanglements in the future. Additionally, bycatch and fisheries gear entanglement is just one of many pressures faced by whales and dolphins globally, with other potential threats including direct take, shipstrike, contaminants, and habitat degradation (IWC 2001). Baleen whales may be particularly sensitive to warming and other future climate change impacts given their slow population growth rates, tight synchrony between life history and water temperatures, and dependency on lower trophic level prey linked directly to primary productivity (Leaper et al. 2006). Given uncertainties in cumulative pressure impacts, conservation efforts must focus on reducing immediate local threats to both dolphin and whale populations to improve resilience.

For small cetaceans, fishing-related mortality is considered the most severe and immediate threat (Jaiteh et al. 2013; Reeves et al. 2013), with global incidental mortality of small cetaceans estimated to be in the region of 300,000 animals each year (Read et al. 2003). Some small cetacean species have been driven towards extinction from unsustainable levels of bycatch (e.g. Vaquita in Mexico (Taylor et al. 2017); Maui and Hector's dolphin in New Zealand (Pala 2017; Pichler and Baker 2000)). Our findings support the universality of the high risk of fatal entanglements faced by small dolphins (Nitta and Henderson 1993), with more than two-thirds of historical interactions involving delphinids, and $>80 \%$ of those resulting in death. Toothed whales and dolphins often target the 
same food source as net-gear fisheries, leading to direct interactions between the animals and gear (Hamer et al. 2008). The numbers of delphinid net fatalities including shark control gear have been shown elsewhere to impact small cetacean populations (Atkins et al. 2016). Most shark nets along the Great Barrier Reef coastline of Queensland have now been replaced by drumlines, which have higher survival rates than nets (Meager and Sumpton 2016; Sumpton et al. 2011).

Mortality rates of Australian humpback and snubfin dolphin shown in this study warrant specific concern. These two newly-recognised endemic species occur in nearshore coastal environments in the northern tropics-subtropics (Palmer et al. 2014; Parra and Cagnazzi 2016), and are listed as Vulnerable by the IUCN Red List (Parra et al. 2017a; Parra et al. 2017b). Coastal dolphins and porpoises are highly susceptible to human activities and environmental change (Brooks et al. 2017; Parra et al. 2006). Although we found small numbers of reported interactions overall $(n=\sim 27)$ for the snubfin and humpback dolphin in Australia, almost $80 \%$ of these have resulted in death. Their coastal distribution combined with small local population sizes (Bejder et al. 2012) is likely to result in high negative impact even from irregular human-induced mortalities. The ongoing humaninduced fatality of vulnerable dolphin species observed here may be unsustainable and warrants further investigation into population sizes and viability to determine the impacts of fisheries interactions, particularly in net and shark control gear. Determining the level of bycatch that avoids negative population impacts, however, is challenging, and additional methods could provide more quantitative estimates for data-limited populations, such as reference point estimation and simulation (Moore et al. 2013). Basic population data on life history or abundance, necessary to calculate reference points, is lacking for the majority of cetaceans found in Australian waters, thus our risk assessment provides the best evaluation given available data.

Fishing effort is typically the main factor influencing bycatch (Dans et al. 2003; Weimerskirch et al. 1997). Our findings corroborate this with lower bycatch associated with reduced effort in some Commonwealth fisheries (e.g. Southern and Eastern Scalefish and Shark Fishery, Fig. S3b). Although there are less fishers in some regions of Australia than historically (Wilkinson 2013), in some regions effort may be increasing, such as the South Australian lobster fishery with now yearround fishing (Linnane et al. 2017). It is likely that the explanatory power of the model for all entanglement records would improve with the inclusion of state commercial fishery effort data, given the strong and significant relationship shown between Commonwealth fisheries effort and bycatch. Fisheries operations may be set to expand in other areas as well, for example salmon aquaculture in Tasmanian waters (Atkin 2014; Kirkpatrick et al. 2017), increasing the risk of interactions with dolphins and whales. More remote offshore areas are now being fished (Moore et al. 2015), shifting the concentration of effort and increasing potential risk to pelagic cetacean species. The size of recreational fishing boats is also increasing across most states of Australia 
680

681

682

683

684

685

686

687

688

689

690

691

692

693

694

695

696

697

698

699

700

701

702

703

704

705

706

707

708

709

710

711

712

713

714

(Lyle et al. 2014; West et al. 2016), and more advanced fishing technology is being used, resulting in potential increases in the amount of gear in the water, which may increase risk of entanglement for coastal species. Increases globally in the amount of gear deployed annually may also increase the potential for entanglements and mortality from the transport of marine rubbish by currents (Pauly et al. 2002), although our findings suggest the overall risk to cetaceans of entanglement in inactive or otherwise floating gear across Australia historically has been considerably less than that of commercial bycatch.

The trends shown in this study likely represent an under-estimate of the true interaction rate, and true mortality rate, between cetaceans and fishing gear in Australian waters. This is because a large proportion of injured or dead cetaceans may never be observed and/or recorded, especially entangled animals moving through remote or offshore areas (Nemiroff et al. 2010) or dead animals that drift away from the coast or that are eaten by scavengers. Recent investigations of whales along the US east coast suggest many more animals are entangled than sightings or reporting would suggest. In the Gulf of Maine, fewer than $10 \%$ of entanglements are reported when compared to analyses of scars on whales in the region (Robbins and Mattila 2004). Furthermore, survival rate of animals after disentanglement in fisheries gear can be low depending on the species, duration of time entangled, handling techniques during rescue operations versus whether the species was able to successfully disentangle themselves, and presence of predators in the water (Mazzuca et al. 1998; Wells et al. 2008). Stranding records show that animals released from entanglement suffering trauma or injury may not recover from the interactions, especially if not all gear is completely removed. We show increasing interventions to release entangled animals may be reducing overall mortality, with fewer fatal interactions in recent years compared to 20 years ago, however numbers of still entangled animals continue to increase. There is substantial evidence from the northern hemisphere that a significant proportion of entanglements of large baleen whales are ultimately fatal if gear is left on the animal (Cassoff et al. 2011; Knowlton et al. 2012). By re-classifying all unreleased records as fatal, we show the risk to cetaceans from entanglements may be much higher than that quantified in this study, with three-quarters of entanglements resulting in death. Despite the growing number of failed rescue operations observed here, due to the inherent challenges of locating and disentangling far-ranging mammals at sea, the value of entanglement response must not be discounted as it may result in the release of important individuals from highly endangered populations, reduction of prolonged suffering for individual animals, and removal of fishing gear which would otherwise remain as harmful marine debris in the ocean (Page et al. 2004).

We show density of human populations along the coast may be driving where and how many entanglements are reported (Figs. 1a, S1). High concentrations of historical incidental records near densely populated capital cities possibly reflects larger numbers of people both in and around the 
water, leading to higher report rates and greater recreational fishing effort, but also better monitoring of cetaceans compared to remote regions, due to the presence and location of conservation agencies, active community groups or whale watching companies (Nemiroff et al. 2010; Norman et al. 2004). Conversely, large geographic gaps in entanglement and bycatch records shown alongside remote areas (Fig. S1) may be attributable to a lack of fisheries-independent observers or other surveillance (Fig. 1a); lower or no fishing effort; inaccessibility, or a lower rate of reporting entanglements, although this would be difficult to quantify. Public sightings of entanglements in states with more remote regions such as Tasmania are unlikely unless from fishers' reports, thus actual interactions may be an order of magnitude higher, Although our remoteness analysis accounts for some reporting bias, this method does not account for factors such as the proximity of humpback migration corridors to major population centres and whether more fishing occurs near major population centres, both of which would drive under-prediction in the remoteness model.

There were uncertainties and limitations involved in this analysis. Heat maps are undoubtedly useful for identifying locations of high rates of entanglements or capture in fixed fishing gear, such as the interaction hotspots identified in this study in shark control gear along the east coast, trap fisheries in the west (see also How et al. 2015), and aquaculture expansion in Tasmania. Spatial fisheries bycatch data, however, were not provided by most jurisdictions across Australia and so are not included in the maps. This means that the true extent of historical fishery-related impacts on cetaceans is under-estimated. For example, large catches of cetaceans have occurred in Australian state commercial fisheries, such as $>200$ delphinids caught in the Pilbara Trawl Fishery over the last 10 years, which extends across the north-west where coldspots were identified, but spatially referenced bycatch data is unavailable. Similarly, $>14,000$ small cetaceans were caught as bycatch in Taiwanese offshore gillnet fisheries during the 1980's across the northern Arafura and Timor Seas where coldspots were identified (Harwood and Hembree 1987), but this data was coarse and lacked fine-scale species information. Furthermore, heat maps may not always be adequate for guiding entanglement mitigation for far-ranging marine wildlife (Tulloch et al. 2015; Wilson et al. 2006), since initial interactions can occur a long distance from where the entangled animal is finally sighted and reported (Bilgmann et al. 2011). For instance, an entangled whale found off the east coast of Australia in an identified entanglement hotspot was trailing gear bearing strong similarities with gear used in the Patagonian Toothfish Fishery in the Southern Ocean (pers. comm. Doug 
750 (including trawl, purse seine, and gillnets) may reduce the high rates of dolphin mortalities

751 observed in this study. Records from sardine purse seine fisheries off SA, within which high levels

752 of common dolphin bycatch have occurred historically (Bilgmann et al. 2011), highlight the

753 effectiveness of changing fishing practices on reducing dolphin interactions, whereby fatal

754 interactions were reduced by $>97 \%$ (from 377 mortalities to $<8$ ) after the introduction of a Code of

755 Practice (Hamer et al. 2008). In the Commonwealth Northern Prawn Fishery more than 50\%

756 reduction in dolphin and turtle bycatch has been achieved since 1998 as a result of effort reductions

757 and mandatory use of bycatch reduction devices and turtle excluder devices, in combination with

758 spatial and temporal closures (AFMA 2013; Fry and Miller 2013). Exclusion grids have also been

759 highly successful in reducing catches of bottlenose dolphins in the Western Australian Pilbara trawl

760 fishery (Stephenson and Wells 2008; Wakefield et al. 2014).

761 The most effective methods of reducing cetacean interactions with fishing gear are those that focus

762 on preventing the entanglements from occurring in the first place (Leaper 2016; Slooten and

763 Dawson 2010), which may require long-term multi-agency and multi-jurisdictional solutions

764 (Derraik 2002; Sheavly and Register 2007). Reduction or elimination of entangling gear out of

765 areas where high densities of vulnerable species occur, such as through spatial closures or effort

766 restriction, can be highly efficient in reducing fisheries interactions (Goldsworthy et al. 2010), but

767 may not always be cost-effective, particularly in areas where high-profit fisheries operate.

768 Nevertheless, reductions in effort in Commonwealth fisheries (Eastern Tuna and Billfish longline,

769 Commonwealth Trawl Sector [CTS] of the SESSF) due to fishery restructures may have driven

770 concomitant reductions in cetacean bycatch between 2006 and 2010 (Tuck et al. 2013), although

771 this may also reflect implementation of spatial and temporal closures in the CTS (AFMA 2014).

772 Recent increases in bycatch likely reflect an increased level of boat monitoring in the fishery

773 through both on-board observer and electronic monitoring (Helidoniotis et al. 2017). In the Gillnet

774 Hook and Trap sector of the SESSF, a rise in reported dolphin bycatch numbers (from 5 in 2008 to

77555 in 2011) led to extensive spatial closures reducing bycatch by two-thirds the following year, and

776 subsequent successful implementation of a Dolphin Management Strategy in 2014, in which fishers

777 incur escalating management responses if dolphin bycatch occurs. Although numerous mitigation

778 measures have been tested and/or implemented globally to reduce risk of capture and mortality of

779 cetaceans in fishery gear (Read 2008; Reeves et al. 2005), these measures do not always work (e.g.

780 Harcourt et al. 2014; Pace et al. 2014). High ongoing entanglements of migrating baleen whales in

781 the Queensland Shark Control Program and of delphinids in the NSW program have not been

782 mitigated through deployments of acoustic alarms or 'pingers', which aim to reduce entanglements

783 (Dalton et al. 2017; Harcourt et al. 2014). In contrast, use of galvanic time releases by the rock

784 lobster trap fishery in NSW, which keep ropes submerged in the lower quarter of the water column 
for the majority of the time, may be keeping cetacean interactions with this fishery low (Werner et al. 2006; Liggins 2018, pers. comm.).

787 The amount of effort invested into monitoring incidental entanglements around Australia has 788 improved in many jurisdictions over the last 10-15 years. However, entanglement databases in 789 Australia are currently managed on a state-by-state basis by separate agencies, without crossjurisdictional consistency or cohesiveness in recording information. The comprehensiveness and accuracy of data collected by each agency on cetacean interactions with fisheries gear thus varies considerably. In many cases, absence of detail in existing records made analysis challenging. Even where records of wildlife are maintained, the quality and consistency of many records limits the ability to compile data in a representative and meaningful way. Furthermore, there is no unified system across Australia for reporting bycatch, nor is there an independent scientific observer program to verify the accuracy of bycatch reporting for all commercial fisheries. Given historical issues of inaccuracies in bycatch reporting by fisheries, our ability to understand and manage entanglements would improve with implementation of standardised fisheries observer programs across jurisdictions, including scrutiny of bycatch reporting.

800 Establishment of a national standardised recording procedure for entanglement incidents and open 801 access data sharing, including greater transparency of state-based commercial fisheries data, would 802 in part resolve issues in analysis identified in this study, as well as reduce potential duplication of 803 data between jurisdictions, and provide better information on outcomes. National and international databases do exist (Atlas of Living Australia 2014; Australian Marine Mammal Centre 2016), but information contained therein lack the breadth and depth needed to fully capture trends in changing pressures on vulnerable species. Information that should be included in any recording of entanglement incidents to enable better evaluation and assignation of the risk to cetaceans would include accurate species identification (including photos for retrospective taxonomic checks), location of reported entanglement and direction of travel of animal, identification of gear and source (e.g. fishery) wherever possible (necessary to target mitigation), and importantly details of any

812 Collation of detailed information on the success of rescue operations is crucial to evaluate their 813 cost-effectiveness as well as look at welfare issues surrounding these responses. A significant 814 problem in analysing incidental entanglement data is an inability to identify the gear and 815 responsible fishery due to a lack of gear identification and/or low level of compliance with 816 requirements to put identification on gear. Given that more than one-quarter of incidental 817 entanglement records in this study could not be identified back to the fishery source, improved 818 initiatives such as collaboration with fishers and fisheries managers on implementing best-practice methods to reduce gear loss on a state-to-state basis and improve the identification of fishing gear 
debris from entanglements by responders are needed.

\section{Conclusion}

823 This study highlights issues relevant for all regions where cetaceans and fisheries co-exist,

824 including the importance of collecting complete, consistent and accurate long-term cetacean

825 entanglement and bycatch data in order to quantify the magnitude of threatening processes.

826 Cetacean incident records such as these can be a good reflection of the composition of wild

827 cetacean populations and the relevant pressures upon them, helping to pinpoint potential regions or

828 fishery types in need of more effective mitigation. We identify limitations in identifying trends in

829 cetacean interactions with fisheries gear from this data both at a local and national level, due to

830 inconsistencies in data collation methods and effort over time and space, low probability of

831 discovery at sea, and under-reporting. We recommend a national approach that includes

832 standardised recording of incidents between cetaceans and fisheries gear; liaising with fishers and

833 fisheries agencies to identify the source of entanglement; ensuring all tools available are used to

834 assess whether mortalities are linked to fishery interactions, and provision of adequate funding to

835 devise and implement effective mitigation wherever possible. Continued efforts to ensure better

836 accuracy and completeness of entanglement and bycatch data at a national level will improve its

837 value as a tool for monitoring cetacean interaction trends, which can be used to provide important

838 information both now and into the future on the status of threatened cetacean species.

\section{Acknowledgements}

841 Funding was provided by the Department of Environment and Energy (DEE). Some spatial

842 information was generously supplied by from our colleagues at AFMA, DOF, DPaW, AAD,

843 DPIPWE (TAS), NSW OEH, DPWS (NSW), NSW DPI, NT Govt, DELWP (VIC), DSE (VIC),

844 DAF, DBCA (WA), South Australian Museum and IWC. We appreciate comments from FRDC and

845 DEE on this manuscript. All agencies thank staff in the departments of environment and fisheries,

846 and the public for reporting events and collecting carcasses. Collection managers from all agencies

847 are thanked for their part in maintaining the collections and databases.

849 Supplementary Material 1: Supplementary methods and figures

850 Supplementary Material 2: Entanglement data used in analyses 


\section{References}

ABS (2011) Australian Statistical Geography Standard (ASGS): Volume 5 - Remoteness Structure (cat. no. 1270.0.55.005).

AFMA (2013) Status Report for re-assessment for export approval under the Environment

Protection and Biodiversity Conservation Act 1999 - Northern Prawn Fishery - October 2013.

AFMA (2014) Shark gillnet bycatch and discarding workplan 2014-2106. Australian Fisheries Management Authority,

AFMA Commonwealth Fisheries Marine Mammal Working Group (CFMMWG) Meeting No 2:

Efficient \& sustainable management of Commonwealth fish resources. In, 2017. p 21

Atkin M (2014) Controversial Plans to Expand Tasmanian Salmon Industry, Environmentalists

Accuse Farms of Polluting Ocean Retrieved from ABC News website: http://www abc net au/news/2014-09-30/controversial-plans-to-expandtasmanian-farmed-salmonindustry/5780140

Atkins S, Cantor M, Pillay N, Cliff G, Keith M, Parra GJ (2016) Net loss of endangered humpback dolphins: integrating residency, site fidelity, and bycatch in shark nets Marine Ecology Progress Series 555:249-260

Atlas of Living Australia (2014) http://www.ala.org.au/

National Marine Mammal Data Portal (2016) https://data.marinemammals.gov.au/. Accessed 8 September 2016

Baulch S, Perry C (2014) Evaluating the impacts of marine debris on cetaceans Marine Pollution Bulletin 80:210-221

Bejder L, Hodgson A, Loneragan N, Allen S (2012) Coastal dolphins in north-western Australia: The need for re-evaluation of species listings and short-comings in the Environmental Impact Assessment process Pacific Conservation Biology 18:22-25

Bilgmann K, Möller LM, Harcourt RG, Kemper CM, Beheregaray LB (2011) The use of carcasses for the analysis of cetacean population genetic structure: a comparative study in two dolphin species PLoS One 6:e20103

Brooks L, Palmer C, Griffiths AD, Pollock KH (2017) Monitoring variation in small coastal dolphin populations: an example from Darwin, Northern Territory, Australia Frontiers in Marine Science 4:94

Bryden M, Marsh H, Shaughnessy PD (1998) Dugongs, whales, dolphins and seals: a guide to the sea mammals of Australia. Allen \& Unwin, Sydney, Australia 
Byrd BL et al. (2014) Strandings as indicators of marine mammal biodiversity and human interactions off the coast of North Carolina Fishery Bulletin 112:1-23

Carroll E et al. (2011) Population structure and individual movement of southern right whales around New Zealand and Australia Marine Ecology Progress Series 432:257-268

Carroll EL et al. (2015) Cultural traditions across a migratory network shape the genetic structure of southern right whales around Australia and New Zealand Scientific reports 5:16182

Cassoff RM, Moore KM, McLellan WA, Barco SG, Rotstein DS, Moore MJ (2011) Lethal entanglement in baleen whales Diseases of aquatic organisms 96:175-185

Chatto R, Warneke RM (2000) Records of cetacean strandings in the Northern Territory of Australia Beagle: Records of the Museums and Art Galleries of the Northern Territory, The $16: 163$

Clapham PJ, \& Baker, C.S. (2002) Modern Whaling. In: Perrin WF, Wursig B, Thewissen JGM (eds) Encyclopedia of Marine Mammals. Academic Press, San Diego, pp 1328-1332

Clapham PJ, Young SB, Brownell RL (1999) Baleen whales: conservation issues and the status of the most endangered populations Mammal review 29:37-62

Commonwealth of Australia (2017) Recovery Plan for Marine Turtles in Australia. Commonwealth of Australia, Canberra.

Dalton S, Peddemors V, Green M (eds) (2017) Shark Meshing (Bather Protection) Program 2016/17 Annual Performance Report. NSW Department of Primary Industries, Australia

Dans SL, Koen Alonso M, Pedraza SN, Crespo EA (2003) Incidental catch of dolphins in trawling fisheries off Patagonia, Argentina: can populations persist? Ecological Applications 13:754762

Davidson AD et al. (2012) Drivers and hotspots of extinction risk in marine mammals Proceedings of the National Academy of Sciences 109:3395-3400

Dayton PK, Thrush SF, Agardy MT, Hofman RJ (1995) Environmental effects of marine fishing Aquatic conservation: marine and freshwater ecosystems 5:205-232

Derraik JG (2002) The pollution of the marine environment by plastic debris: a review Marine Pollution Bulletin 44:842-852

Fletcher W, J, Chesson J, M. F, Sainsbury KJ, Hundloe T, Smith ADM, Whitworth B (2002)

National ESD Reporting Framework for Australian Fisheries: The 'How To' Guide for Wild Capture Fisheries. FRDC Project 2000/145. Canberra, Australia

Fry G, Miller M (2013) Appendix 7. Northern Prawn Fishery. Canberra

Goldsworthy SD, Page B, Shaughnessy PD, Linnane A (2010) Mitigating Seal Interactions in the SRLF and the Gillnet Sector SESSF in South Australia. Report to the Fisheries Research and Development Institute. South Australian Research and Development Institute (Aquatic 
Sciences), Adelaide SARDI Publication No F2009/000613-1 SARDI Research Report Series No 405

Green M, Ganassin C, Reid DD (2009) Report into the NSW Shark Meshing (Bather Protection) Program. Fisheries Conservation and Aquaculture Branch, Orange NSW

Groom C, Coughran D (2012) Entanglements of baleen whales off the coast of Western Australia between 1982 and 2010: patterns of occurrence, outcomes and management responses Pacific Conservation Biology 18:203

Guenther TJ, Baird RW, Bates RL, Willis PM, Hahn RL, Wischniowski SG (1995) Strandings and fishing gear entanglements of cetaceans off the west coast of Canada in 1994 International Whaling Commission Document SC/47/O

Guenther TJ, Baird RW, Ford JK, Langelier KM, McAdie ML, Wishniowski SG, Cornish TE (1993) Cetacean strandings and entanglement in fishing gear on the west coast of Canada during 1992 International Whaling Commission Meeting Document SC/45/O

Hamer DJ, Ward TM, McGarvey R (2008) Measurement, management and mitigation of operational interactions between the South Australian Sardine Fishery and short-beaked common dolphins (Delphinus delphis) Biological Conservation 141:2865-2878

Harcourt R, Aurioles D, Sanchez J (1994) Entanglement of California sea lions at los islotes, Baja California Sur, México Marine Mammal Science 10:122-125

Harcourt R, Pirotta V, Heller G, Peddemors V, Slip D (2014) A whale alarm fails to deter migrating humpback whales: an empirical test Endangered Species Research 25:35-42

Harwood J (2000) Risk assessment and decision analysis in conservation Biol Conserv 95:219-226 Harwood M, Hembree D (1987) Incidental Catch of Small Cetaceans in the Offshore Gillnet Fishery in Northern Australian Waters 1981-1985 Report of the International Whaling Commission 37

Helidoniotis F, Koduah A, Nicol S (2017) Southern and Eastern Scalefish and Shark Fishery. How $\mathbf{J}$ et al. (2015) Effectiveness of mitigation measures to reduce interactions between commercial fishing gear and whales. FRDC Project No 2013/03. Department of Fisheries, Western Australia

Hugo Centre (2014) Accessibility/Remoteness Index of Australia Plus 2011 (ARIA+ 2011). Hugo Centre for Migration and Population Research, the University of Adelaide. Adelaide, South Australia

ICES (2017) Bycatch of small cetaceans and other marine animals-Review of national reports under Council Regulation (EC) No. 812/2004 and other information. 
IWC (2001) Report of the workshop on the comprehensive assessment of right whales: a worldwide comparison. International Whaling Commission Journal of Cetacean Research and Management Special Issue 2:1-60

IWC (2010) Report of the Workshop on Welfare Issues Associated with the Entanglement of Large Whales. IWC Document IWC/62/15.

IWC (2016) Annex J: Report of the Working Group on Non-deliberate Human-induced Mortality of Cetaceans. Report of the Scientific Committee. IWC/66/Rep01.

Jackson J et al. (2015) Southern Hemisphere humpback whale comprehensive assessment—a synthesis and summary: 2005-2015 (received) Paper SC/66a/SH03 presented to the IWC Scientific Committee

Jaiteh VF, Allen SJ, Meeuwig JJ, Loneragan NR (2013) Subsurface behavior of bottlenose dolphins (Tursiops truncatus) interacting with fish trawl nets in northwestern Australia: Implications for bycatch mitigation Marine Mammal Science 29

Johnson A, Salvador G, John K, Robbins J, Kraus S, Landry S, Clapham P (2005) Fishing gear involved in entanglements of right and humpback whales Marine Mammal Science 21:635645

Kemper C, Coughran D, Warneke R, Pirzl R, Watson M, Gales R, Gibbs S (2008) Southern right whale (Eubalaena australis) mortalities and human interactions in Australia, 1950-2006 Journal of Cetacean Research and Management 10:1-8

Kirkpatrick JB, Kriwoken LK, Styger J (2017) The reverse precautionary principle: science, the environment and the salmon aquaculture industry in Macquarie Harbour, Tasmania, Australia Pacific Conservation Biology

Kirkwood J, Bennett P, Jepson P, Kuiken T, Simpson V, Baker J (1997) Entanglement in fishing gear and other causes of death in cetaceans stranded on the coasts of England and Wales Veterinary Record 141:94-98

Knowlton AR, Hamilton PK, Marx MK, Pettis HM, Kraus SD (2012) Monitoring North Atlantic right whale Eubalaena glacialis entanglement rates: a 30 yr retrospective Marine Ecology Progress Series 466:293-302

Kraus SD et al. (2005) North Atlantic right whales in crisis Science 309:561-562

Laist DW (1997) Impacts of marine debris: entanglement of marine life in marine debris including a comprehensive list of species with entanglement and ingestion records. In: Marine Debris. Springer, pp 99-139

Leaper R (2016) Review of methods used to reduce risks of large whale entanglements. SC/66b/HIM07 
Leaper R, Cooke J, Trathan P, Reid K, Rowntree V, Payne R (2006) Global climate drives southern right whale (Eubalaena australis) population dynamics Biol Lett 2:289-292

Lewison RL, Crowder LB, Read AJ, Freeman SA (2004) Understanding impacts of fisheries bycatch on marine megafauna Trends in Ecology \& Evolution 19:598-604

Linnane A, McLeay L, McGarvey R, Jones A (2017) Industry-Supported Sampling Underpins Temporal Management Policy Change in a Commercial Rock Lobster (Jasus edwardsii) Fishery Journal of Shellfish Research 36:511-517

Lloyd HB, Ross GA (2015) Long-term trends in cetacean incidents in New South Wales, Australia Australian Zoologist 37:492-500

Lyle JM, Stark KE, Tracey SR (2014) 2012-13 survey of recreational fishing in Tasmania. Institute for Marine and Antarctic Studies, University of Tasmania,

Mazzuca L, Atkinson S, Nitta E (1998) Deaths and entanglements of humpback whales, Megaptera novaeangliae, in the main Hawaiian Islands, 1972-1996

Meager JJ, Sumpton WD (2016) Bycatch and strandings programs as ecological indicators for datalimited cetaceans Ecological Indicators 60:987-995

Moore A et al. (2015) Developing robust and cost-effective methods for estimating the national recreational catch of Southern Bluefin Tuna in Australia

Moore J et al. (2013) Evaluating sustainability of fisheries bycatch mortality for marine megafauna: a review of conservation reference points for data-limited populations Environmental Conservation 40:329-344

Moore JE, Wallace BP, Lewison RL, Žydelis R, Cox TM, Crowder LB (2009) A review of marine mammal, sea turtle and seabird bycatch in USA fisheries and the role of policy in shaping management Marine Policy 33:435-451

Moore MJ, Van der Hoop JM (2012) The painful side of trap and fixed net fisheries: chronic entanglement of large whales Journal of Marine Biology 2012

Myers RA, Worm B (2003) Rapid worldwide depletion of predatory fish communities Nature 423:280-283 doi:Doi 10.1038/Nature01610

National Marine Fisheries Service (2016) U.S. National Bycatch Report First Edition Update 2. US Department of Commerce,

Nemiroff L, Wimmer T, Daoust P-Y, McAlpine DF (2010) Cetacean strandings in the Canadian Maritime provinces, 1990-2008 The Canadian Field-Naturalist 124:32-44

Nitta ET, Henderson JR (1993) A review of interactions between Hawaii's fisheries and protected species Marine Fisheries Review 55:83-92

NOAA (2016) 2016 West Coast entanglement summary. National Oceanic \& Atmospheric Administration, 
Noad MJ, Dunlop RA, Bennett L, H K (2016) Abundance estimates of the east Australian humpback whale population (BSE1): 2015 survey update. Progress report to the International Whaling Commission SC/66b/SH/21:1:10.

Noad MJ, Dunlop RA, Paton D, Cato DH (2011) Absolute and relative abundance estimates of Australian east coast humpback whales (Megaptera novaeangliae) Journal of Cetacean Research Management Special Issue 3:243-252

Norman S et al. (2004) Cetacean strandings in Oregon and Washington between 1930 and 2002 Journal of Cetacean Research and Management 6:87-100

Pace RM, Cole TV, Henry AG (2014) Incremental fishing gear modifications fail to significantly reduce large whale serious injury rates Endangered Species Research 26:115-126

Pace RM, Corkeron PJ, Kraus SD (2017) State-space mark-recapture estimates reveal a recent decline in abundance of North Atlantic right whales Ecology and Evolution 7:8730-8741

Page B et al. (2004) Entanglement of Australian sea lions and New Zealand fur seals in lost fishing gear and other marine debris before and after Government and industry attempts to reduce the problem Marine Pollution Bulletin 49:33-42

Pala C (2017) New Zealand's endemic dolphins are hanging by a thread Science 355:559-559 doi:10.1126/science.355.6325.559

Palmer C, Parra GJ, Rogers T, Woinarski J (2014) Collation and review of sightings and distribution of three coastal dolphin species in waters of the Northern Territory, Australia Pacific Conservation Biology 20:116-125

Parra GJ, Cagnazzi D (2016) Conservation status of the Australian humpback dolphin (Sousa sahulensis) using the IUCN Red List Criteria. In: Advances in marine biology, vol 73. Elsevier, pp 157-192

Parra GJ, Cagnazzi D, Beasley I (2017a) Orcaella heinsohni. The IUCN Red List of Threatened Species 2017: e.T136315A50385982.

Parra GJ, Cagnazzi D, Perrin WF, Braulik GT (2017b) Sousa sahulensis: The IUCN Red List of Threatened Species 2017: e.T82031667A82031671.

Parra GJ, Corkeron PJ, Marsh H (2006) Population sizes, site fidelity and residence patterns of Australian snubfin and Indo-Pacific humpback dolphins: Implications for conservation Biological conservation 129:167-180

Pauly D (2009) Beyond duplicity and ignorance in global fisheries Scientia Marina (Barcelona) $73: 215-224$

Pauly D et al. (2002) Towards sustainability in world fisheries Nature 418:689 
Pichler F, Baker C (2000) Loss of genetic diversity in the endemic Hector's dolphin due to fisheries-related mortality Proceedings of the Royal Society of London B: Biological Sciences 267:97-102

Pikesley SK, Witt MJ, Hardy T, Loveridge J, Loveridge J, Williams R, Godley BJ (2012) Cetacean sightings and strandings: evidence for spatial and temporal trends? Journal of the Marine Biological Association of the United Kingdom 92:1809-1820

Productivity Commission (2016) Marine Fisheries and Aquaculture, Final Report. Australian Government, Canberra

Read AJ (2008) The looming crisis: interactions between marine mammals and fisheries Journal of Mammalogy 89:541-548

Read AJ, Drinker P, Northridge S (2003) By-catches of marine mammals In U.S. fisheries and a first attempt to estimate the magnitude of global marine mammal by-catch. International Whaling Commission paper SC/55/BC5.

Read AJ, Drinker P, Northridge S (2006) Bycatch of marine mammals in US and global fisheries Conserv Biol 20:163-169

Reeves RR et al. (2005) Global priorities for reduction of cetacean bycatch World Wildlife Fund

Reeves RR, McClellan K, Werner TB (2013) Marine mammal bycatch in gillnet and other entangling net fisheries, 1990 to 2011 Endangered Species Research 20:71-97

Reid D, Krogh M (1992) Assessment of catches from protective shark meshing off NSW beaches between 1950 and 1990 Marine and Freshwater Research 43:283-296

Reid D, Robbins W, Peddemors V (2011) Decadal trends in shark catches and effort from the New South Wales, Australia, Shark Meshing Program 1950-2010 Marine and Freshwater Research 62:676-693

Reisser J, Shaw J, Wilcox C, Hardesty BD, Proietti M, Thums M, Pattiaratchi C (2013) Marine Plastic Pollution in Waters around Australia: Characteristics, Concentrations, and Pathways PLOS ONE 8:e80466 doi:10.1371/journal.pone.0080466

Robbins J, Mattila D (2004) Estimating humpback whale (Megaptera novaeangliae) entanglement rates on the basis of scar evidence Final report Northeast Fisheries Science Center, Woods Hole, Massachusetts

Ross GJB (2006) Review of the Conservation Status of Australia's Smaller Whales and Dolphins.

Page(s) 124. Report to the Australian Department of the Environment and Heritage, Canberra. Available from: http://www.environment.gov.au/resource/reviewconservation-status-australias-smaller-whales-and-dolphins. 
Salgado Kent CP, Jenner C, Jenner M, Bouchet P, Rexstad E (2012) Southern Hemisphere breeding stock D humpback whale population estimates from North West Cape, Western Australia J Cetacean Res Manage 12:29-38

Scheld AM, Bilkovic DM, Havens KJ (2016) The dilemma of derelict gear Scientific reports 6:19671

Schipper J et al. (2008) The status of the world's land and marine mammals: diversity, threat, and knowledge Science 322:225-230

Segawa T, Kemper C (2015) Cetacean strandings in South Australia (1881-2008) Australian Mammalogy 37:51-66

Sheavly S, Register K (2007) Marine debris \& plastics: environmental concerns, sources, impacts and solutions Journal of Polymers and the Environment 15:301-305

Slooten E, Dawson SM (2010) Assessing the effectiveness of conservation management decisions: likely effects of new protection measures for Hector's dolphin (Cephalorhynchus hectori) Aquatic Conservation: Marine and Freshwater Ecosystems 20:334-347

Slooten E, Fletcher D, Taylor BL (2000) Accounting for uncertainty in risk assessment: case study of Hector's dolphin mortality due to gillnet entanglement Conservation Biology 14:12641270

Stephenson PC, Wells S (2008) Evaluation of the effectiveness of reducing dolphin catches with pingers and exclusion grids in the Pilbara trawl fishery. Department of Fisheries Western Australia. Fisheries Research Report No. 173.

Sumpton WD, Taylor SM, Gribble NA, McPherson G, Ham T (2011) Gear selectivity of largemesh nets and drumlines used to catch sharks in the Queensland Shark Control Program African Journal of Marine Science 33:37-43

Taylor BL, Martinez M, Gerrodette T, Barlow J, Hrovat YN (2007) Lessons from monitoring trends in abundance of marine mammals Marine Mammal Science 23:157-175

Taylor BL et al. (2017) Extinction is imminent for Mexico's endemic porpoise unless fishery bycatch is eliminated Conservation Letters 10:588-595

Tønnessen JN, Johnsen AO (1982) The history of modern whaling. C. Horst \& Co., London Tuck GN, Knuckey I, Klaer NL (2013) Informing the review of the Commonwealth Policy on Fisheries Bycatch through assessing trends in bycatch of key Commonwealth fisheries. Fisheries Research and Development Corporation final report 2012/046.

Tulloch VJD, Plagányi ÉE, Matear R, Brown CJ, Richardson AJ (2017) Ecosystem modelling to quantify the impact of historical whaling on Southern Hemisphere baleen whales Fish Fish doi: 10.1111/faf.12241 doi:10.1111/faf.12241 
Tulloch VJD et al. (2015) Why do we map threats? Linking threat mapping with actions to make better conservation decisions Front Ecol Environ 13:91-99 doi:10.1890/140022

Van Der Hoop JM et al. (2013) Assessment of management to mitigate anthropogenic effects on large whales Conserv Biol 27:121-133

Wakefield CB et al. (2014) Independent observations of catches and subsurface mitigation efficiencies of modified trawl nets for endangered, threatened and protected megafauna bycatch in the Pilbara Fish Trawl Fishery. Fisheries Research Report No. 244. Department of Fisheries, Western Australia

Waring GT, Josephson E, Maze-Foley K, Rosel PE (2013) US Atlantic and Gulf of Mexico Marine Mammal Stock Assessments 2012. Citeseer,

Weimerskirch H, Brothers N, Jouventin P (1997) Population dynamics of wandering albatross Diomedea exulans and Amsterdam albatross D. amsterdamensis in the Indian Ocean and their relationships with long-line fisheries: conservation implications Biological conservation 79:257-270

Wells RS et al. (2008) Consequences of injuries on survival and reproduction of common bottlenose dolphins (Tursiops truncatus) along the west coast of Florida Marine Mammal Science 24:774-794

Werner T, Kraus S, Read A, Zollett E (2006) Fishing techniques to reduce the bycatch of threatened marine animals Marine Technology Society Journal 40:50-68

Werner TB, Northridge S, Press KM, Young N (2015) Mitigating bycatch and depredation of marine mammals in longline fisheries ICES Journal of Marine Science 72:1576-1586

West LD, Stark KE, Murphy JJ, Lyle JM, Ochwada-Doyle FA (2016) Survey of recreational fishing in New South Wales and the ACT, 2013/14, Fisheries Final Report Series, no. 149. NSW Department of Primary Industries, Cronulla, Sydney,

Wilkinson J (2013) NSW Commercial Fishing Industry: background to the 2012 review. Briefing Paper No. 2/2013.

Wilson KA, McBride MF, Bode M, Possingham HP (2006) Prioritizing global conservation efforts Nature 440:337-340 doi:Doi 10.1038/Nature04366

Wood SN (2006) Generalized Additive Models: An Introduction With R. Chapman \& Hall/CRC, Boca Raton

\section{Figure captions}

Figure 1. a) Map of Australia, identifying states and territories $(\mathrm{NT}=$ Northern Territory, WA $=$ Western Australia, SA = South Australia, QLD = Queensland, NSW = New South Wales, VIC = 
Victoria, TAS = Tasmania), and remoteness index on the land, where the darkest shade on land indicates densely populated areas (major cities), through to the lightest grey which indicates very remote areas; and hotspots of reported entanglements pooled for: b) all taxa and years, c) listed threatened or migratory cetacean species, d) difference map of entanglement hotspots identifying regions of higher baleen whale entanglements (orange) versus toothed whales or dolphins (green), and e) recorded mortalities from entanglement, with highest number of dead or still entangled entanglements in dark blue, and low mortality $(<=1)$ in yellow. Hotspots are at a $1 / 2$ degree resolution, for all records with spatial data.

Figure 2. Number of entanglements per year for a) toothed whales and dolphins (light grey), baleen whales (black), and unidentified species (dark grey), pooled, across all jurisdictions; b) showing the best-fit model for data excluding fisheries bycatch, where the solid line is the smoother from the final GAMM model and the shaded area represents the 95\% confidence intervals, and the rugs on the $\mathrm{x}$ axis represent years where data were available; and c) seasonal differences in the number of entanglements for toothed whales and dolphins (grey) and baleen whales (black). Note the low numbers in 2016 reflect incomplete records received for that year.

Figure 3. Average annual entanglement rate for each state/territory $(\mathrm{NT}=$ Northern Territory, WA = Western Australia, SA = South Australia, QLD = Queensland, NSW = New South Wales, VIC = Victoria, TAS = Tasmania, C'wealth = Commonwealth [Australia]), derived by dividing the number of reported entanglements by the number of years since data has been regularly collected (Supp. Table S1), for 1986-1995 (dark grey bars), 1996-2005 (light bars), and 2006-2015 (black bars), for a) incidental reported entanglements state agency databases and International Whaling Commission (IWC) records), and b) all records (including Commonwealth fisheries records and commercial fisheries data where available). Note the different vertical axes.

Figure 4. Fate of cetaceans involved in entanglements, pooled across all jurisdictions, for all data including incidental and vessel-based records (Commonwealth fisheries records from logbook entries), showing a) the number of records for fatal entanglements (red squares), disentanglement (green squares), and still entangled (blue triangles) by year, b) trends in these fates as a proportion of total entanglements by year from 1990 when reporting effort increased, and c) linear regression of rate of interventions relative to overall mortality showing increasing numbers of interventions may be related to reductions in overall mortality.

Figure 5. Number of entanglements relative to gear type between 1990 and 2016 and animals' fate, 
for baleen whales (a), and dolphins and toothed whales (b). Records excluded for animals not identified to suborder $(n=31)$. Note different scales of the $y$-axis.

Figure 6. Proportion of each gear responsible for cetacean entanglements by state/territory $(\mathrm{NT}=$ Northern Territory, WA $=$ Western Australia, SA $=$ South Australia, QLD = Queensland, NSW = New South Wales, VIC = Victoria, TAS = Tasmania), for all entanglement data from 1887 to 2016. Size of the chart is relative to the number of entanglement records for each State.

Table 1. Number of entanglements for each species and jurisdiction, from 1887 to 2016, including live releases from fisheries, and listing under the IUCN Red List and EPBC Act (NA - Not Assessed, DD- Data deficient, LC - Least Concern, NT - Near Threatened, VU - Vulnerable, EN Endangered; MC - Migratory Cetacean; CE - Cetacean listing only).

Table 2. Ecological risk assessment for species with historical entanglements in fisheries gear in Australian waters, identifying species at high risk of entanglements (red) versus low risk (green). See Supplementary Table S3 for inputs into quantitative assessment of entanglement data by gear type.

Table 3. Management intervention, success, and fate of individual animals 


\section{Table 1}

\begin{tabular}{|c|c|c|c|c|c|c|c|c|c|c|c|c|}
\hline Name & Species name & $\begin{array}{l}\text { IUCN } \\
\text { status }\end{array}$ & $\begin{array}{l}\text { EPBC } \\
\text { status }\end{array}$ & Cwlth $^{1}$ & NSW & NT & Qld & $\mathbf{S A}$ & TAS & VIC & WA & TOTAL \\
\hline \multicolumn{13}{|c|}{$\begin{array}{l}\text { MYSTICETI (Baleen whales) } \\
\text { (families Balaenopteridae and Balaenidae) }\end{array}$} \\
\hline Antarctic minke whale & Balaenoptera bonaerensis & DD & $\mathrm{MC}$ & 0 & 0 & 0 & 1 & 0 & 0 & 0 & 0 & 1 \\
\hline Blue whale & Balaenoptera musculus & EN & EN, MC & 1 & 0 & 0 & 0 & 0 & 0 & 1 & 0 & 2 \\
\hline Bryde's whale & Balaenoptera edeni & DD & $\mathrm{MC}$ & 0 & 0 & 0 & 0 & 0 & 0 & 0 & 1 & 1 \\
\hline Common minke whale & Balaenoptera acutorostrata & LC & $\mathrm{CE}$ & 0 & 2 & 0 & 0 & 0 & 0 & 0 & 1 & 3 \\
\hline Humpback whale & Megaptera novaeangliae & LC & VU, MC & 2 & 159 & 0 & 106 & 1 & 9 & 9 & 150 & 436 \\
\hline Pygmy right whale & Caperea marginata & DD & $\mathrm{MC}$ & 0 & 0 & 0 & 0 & 1 & 0 & 1 & 0 & 2 \\
\hline Southern right whale & Eubalaena australis & LC & EN, MC & 0 & 4 & 0 & 0 & 4 & 5 & 5 & 10 & 28 \\
\hline Unidentified whale & & & & 1 & 0 & 1 & 40 & 0 & 0 & 0 & 0 & 42 \\
\hline Mysticeti Total & & & & 4 & 165 & 1 & 147 & 6 & 14 & 16 & 162 & 515 \\
\hline \multicolumn{13}{|c|}{ ODONTOCETI (Toothed whales and dolphins) } \\
\hline \multicolumn{13}{|l|}{ Beaked whales (family Ziphiidae) } \\
\hline Strap-toothed beaked whale & Mesoplodon layardii & DD & $\mathrm{CE}$ & 0 & 0 & 0 & 0 & 1 & 0 & 0 & 0 & 1 \\
\hline Unidentified beaked whale & & & & 2 & 0 & 0 & 0 & 0 & 0 & 0 & 0 & 2 \\
\hline \multicolumn{13}{|c|}{ Toothed whales (families Kogiidae and Physeteridae) } \\
\hline Pygmy sperm whale & Kogia breviceps & DD & $\mathrm{CE}$ & 0 & 0 & 0 & 0 & 1 & 0 & 0 & 0 & 1 \\
\hline Sperm whale & Physeter macrocephalus & VU & MC & 35 & 0 & 0 & 0 & 4 & 0 & 0 & 0 & 39 \\
\hline \multicolumn{13}{|c|}{ Dolphins and small toothed whales (family Delphinidae) } \\
\hline Australian humpback dolphin & Sousa sahulensis & VU & VU, MC & 0 & 0 & 0 & 27 & 0 & 0 & 0 & 0 & 27 \\
\hline Australian snubfin dolphin & Orcaella heinsohni & VU & VU, MC & 0 & 0 & 2 & 13 & 0 & 0 & 0 & 0 & 15 \\
\hline Common bottlenose dolphin & Tursiops truncates & LC & $\mathrm{CE}$ & 4 & 25 & 0 & 7 & 0 & 6 & 0 & 48 & 90 \\
\hline False killer whale & Pseudorca crassidens & DD & $\mathrm{CE}$ & 1 & 4 & 0 & 1 & 0 & 0 & 0 & 1 & 7 \\
\hline Indo-Pacific bottlenose dolphin & Tursiops aduncus & DD & $\mathrm{MC}^{*}$ & 0 & 2 & 0 & 18 & 45 & 0 & 3 & 0 & 68 \\
\hline Killer whale & Orcinus orca & DD & $\mathrm{MC}$ & 30 & 0 & 0 & 0 & 0 & 0 & 0 & 0 & 30 \\
\hline Long-finned pilot whale & Globicephala melas & DD & $\mathrm{CE}$ & 0 & 0 & 0 & 0 & 1 & 0 & 0 & 0 & 1 \\
\hline Melon-headed whale & Peponocephala electra & LC & $\mathrm{CE}$ & 5 & 0 & 0 & 0 & 0 & 0 & 0 & 0 & 5 \\
\hline Pantropical spotted dolphin & Stenella attenuata & LC & $\mathrm{MC}$ & 0 & 0 & 3 & 0 & 0 & 0 & 0 & 0 & 3 \\
\hline Pygmy killer whale & Feresa attenuata & DD & $\mathrm{CE}$ & 1 & 1 & 0 & 0 & 0 & 0 & 0 & 0 & 2 \\
\hline Risso's dolphin & Grampus griseus & DD & $\mathrm{CE}$ & 0 & 1 & 0 & 0 & 0 & 0 & 0 & 0 & 1 \\
\hline
\end{tabular}

${ }^{1}$ Commonwealth fisheries records from logbook data only

*Arafura/Timor Sea population 


\begin{tabular}{|c|c|c|c|c|c|c|c|c|c|c|c|c|}
\hline Short-beaked common dolphin & Delphinus delphis & LC & $\mathrm{CE}$ & 28 & 35 & 0 & 178 & 95 & 16 & 3 & 60 & 415 \\
\hline Short-finned pilot whale & Globicephala macrorhynchus & DD & $\mathrm{CE}$ & 21 & 0 & 0 & 0 & 0 & 0 & 0 & 0 & 21 \\
\hline Southern bottlenose whale & Hyperoodon planifrons & LC & $\mathrm{CE}$ & 1 & 0 & 0 & 0 & 0 & 0 & 0 & 0 & 1 \\
\hline Spinner dolphin & Stenella longirostris & DD & $\mathrm{CE}$ & 0 & 0 & 3 & 11 & 0 & 0 & 0 & 0 & 14 \\
\hline Striped dolphin & Stenella coeruleoalba & LC & $\mathrm{CE}$ & 0 & 0 & 0 & 0 & 0 & 1 & 0 & 0 & 1 \\
\hline $\begin{array}{l}\text { Undifferentiated bottlenose } \\
\text { dolphin }\end{array}$ & Tursiops spp. & & & 0 & 11 & 12 & 52 & 5 & 0 & 1 & 85 & 165 \\
\hline Unidentified dolphin & & & & 187 & 33 & 0 & 52 & 51 & 1 & 1 & 157 & 482 \\
\hline Unidentified pilot whale & & & & 0 & 0 & 0 & 0 & 1 & 1 & 0 & 0 & 2 \\
\hline Unidentified toothed whale & & & & 6 & 0 & 0 & 28 & 0 & 0 & 0 & 0 & 6 \\
\hline Odontoceti Total & & & & 321 & 112 & 20 & 387 & 204 & 25 & 8 & 351 & 1428 \\
\hline Unidentified cetacean & & & & 20 & 14 & 0 & 0 & 0 & 1 & 0 & 9 & 44 \\
\hline Grand Total & & & & 345 & 291 & 21 & 533 & 210 & 40 & 24 & 522 & 1987 \\
\hline
\end{tabular}


Table 2.

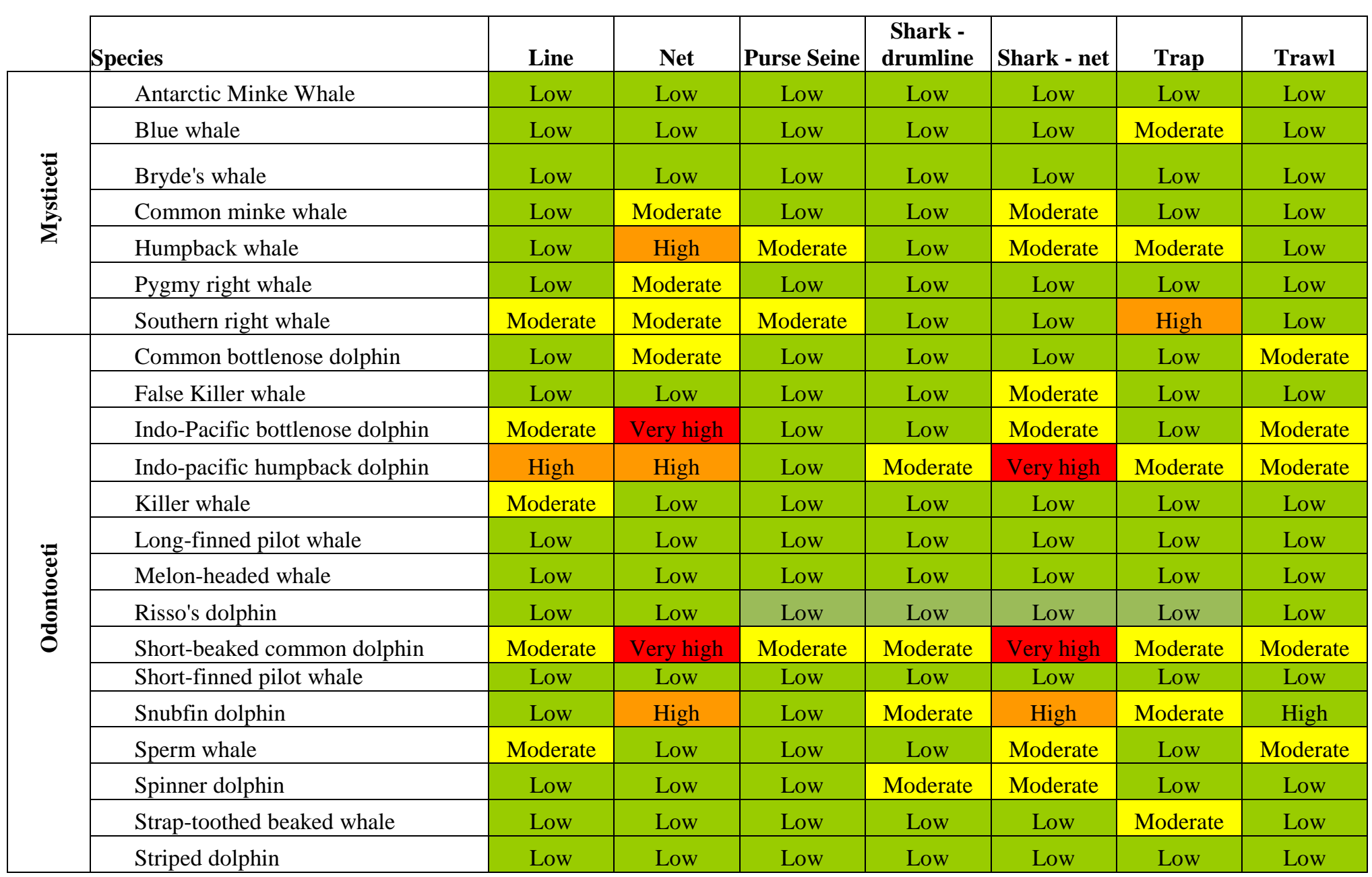


Table 3.

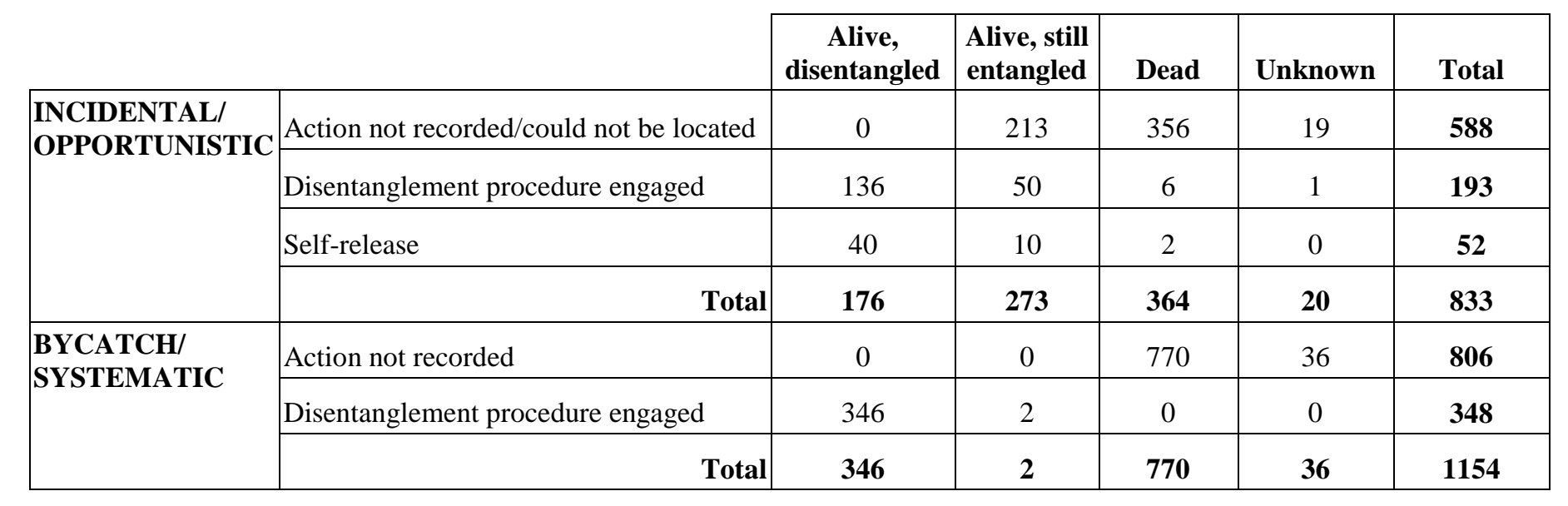


a)

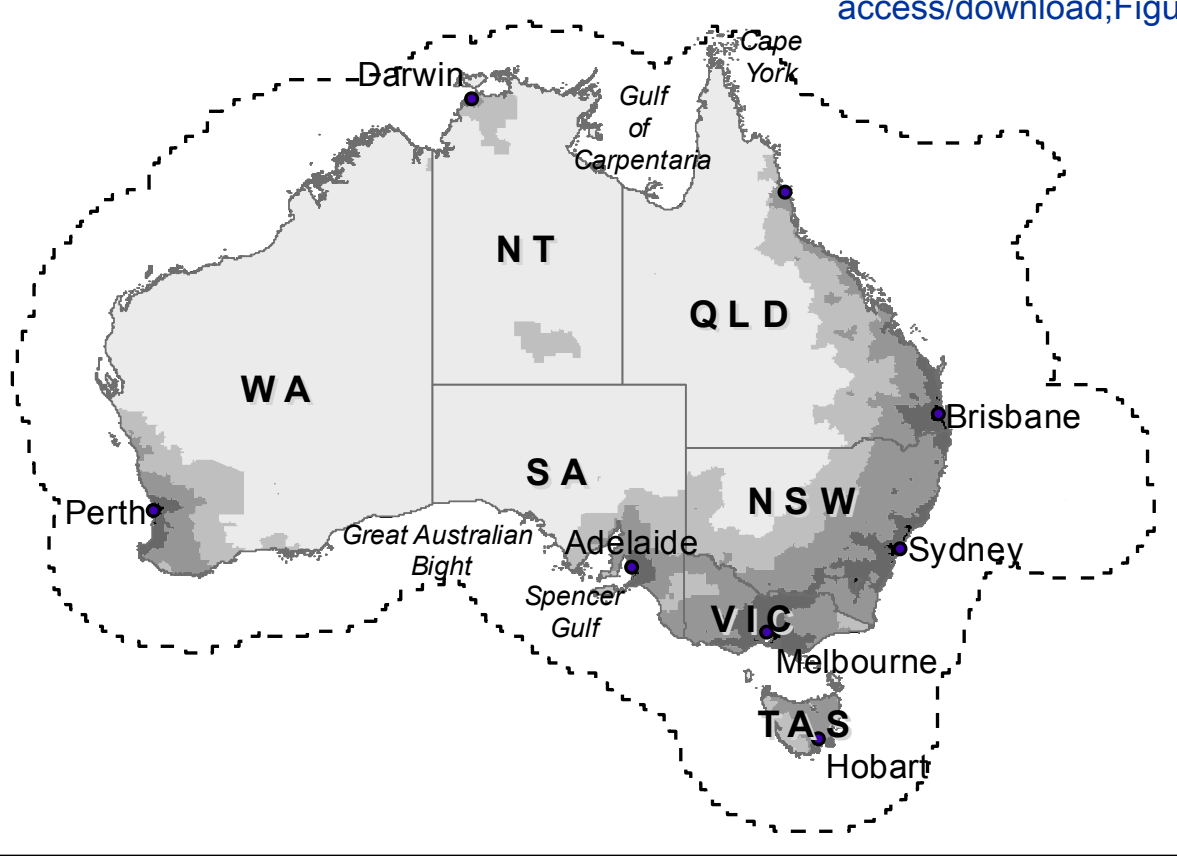

- Capital cities

\section{Remoteness index}

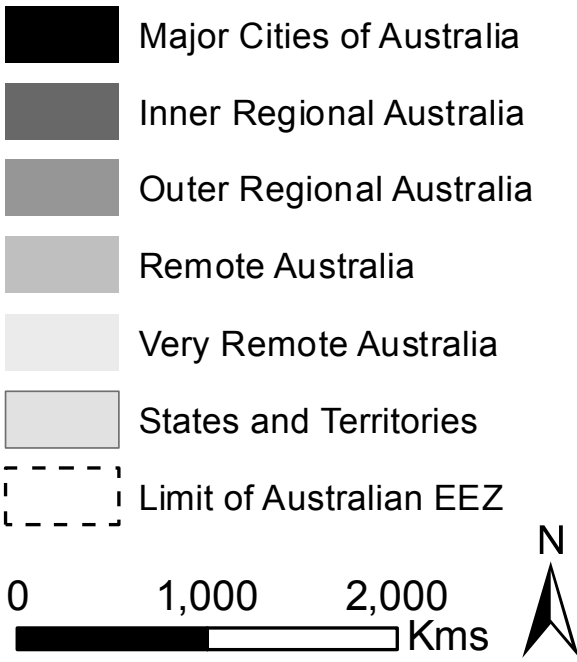

b)

No. of entanglements - total

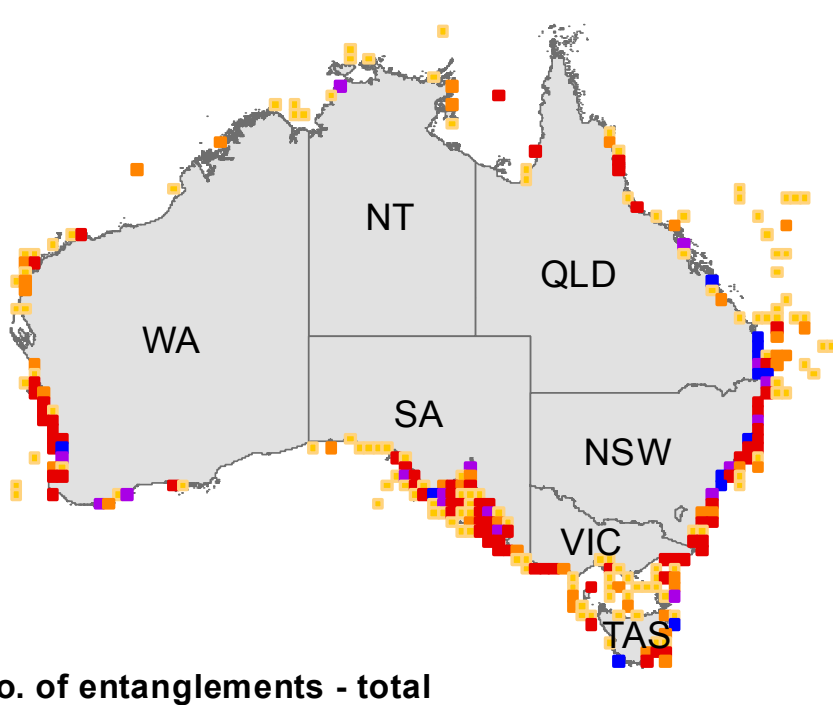

$123^{10} \wedge^{2} 2^{2}, 5^{50}$

d)

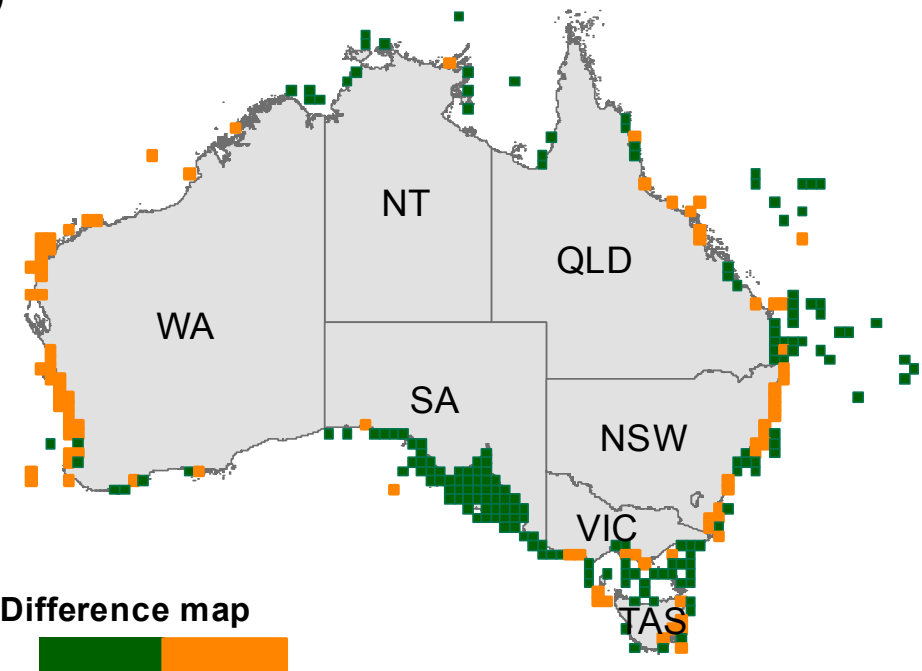

c)

No. of entanglements - listed spp.

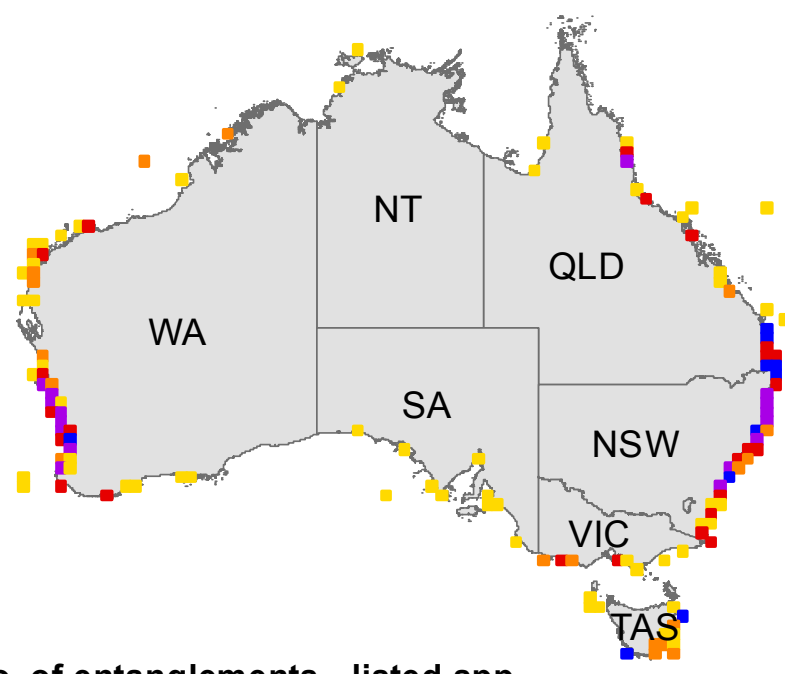

$\sqrt{2} 3^{5} 6^{10} 1^{1 x^{2}}$

e)
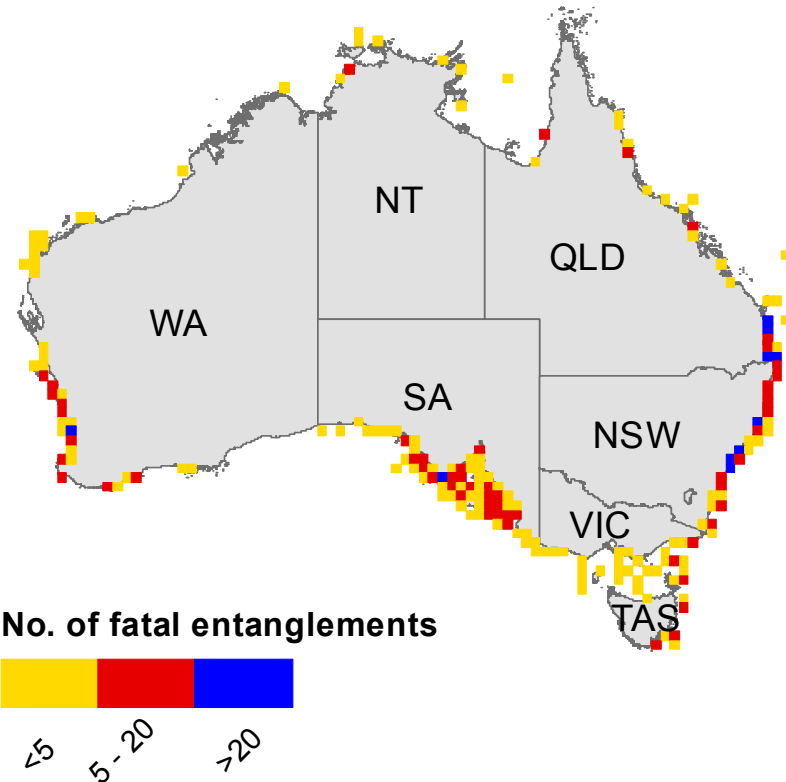
a)

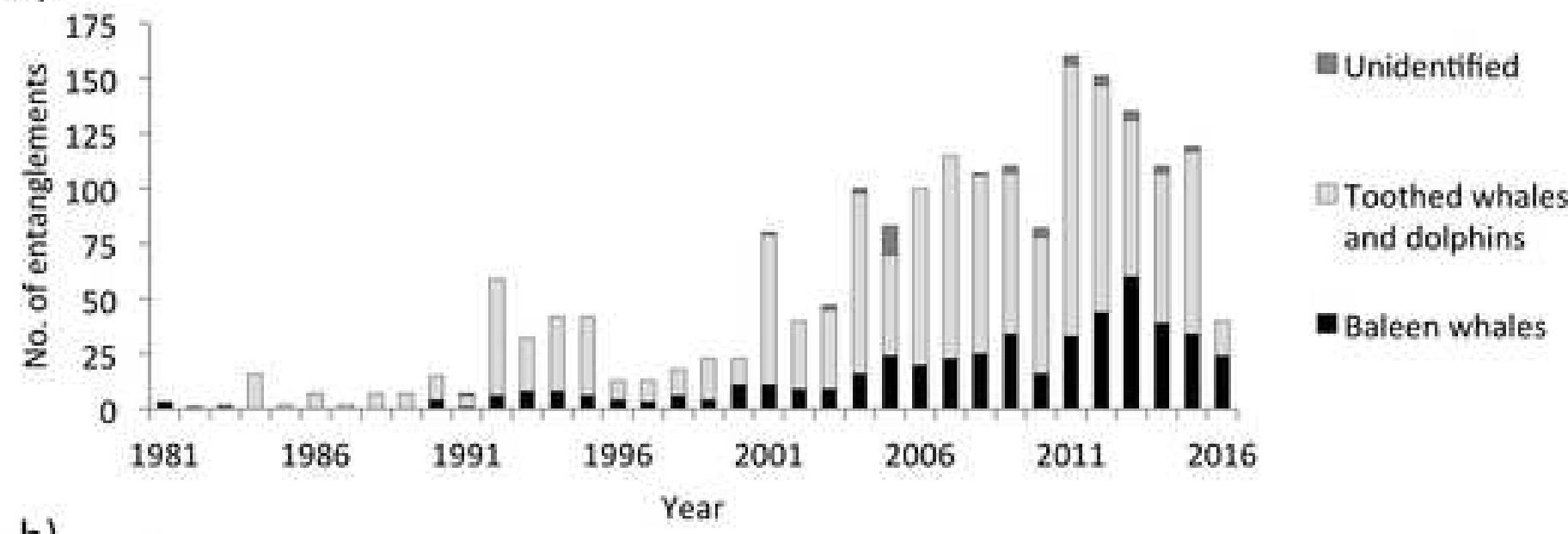

b)

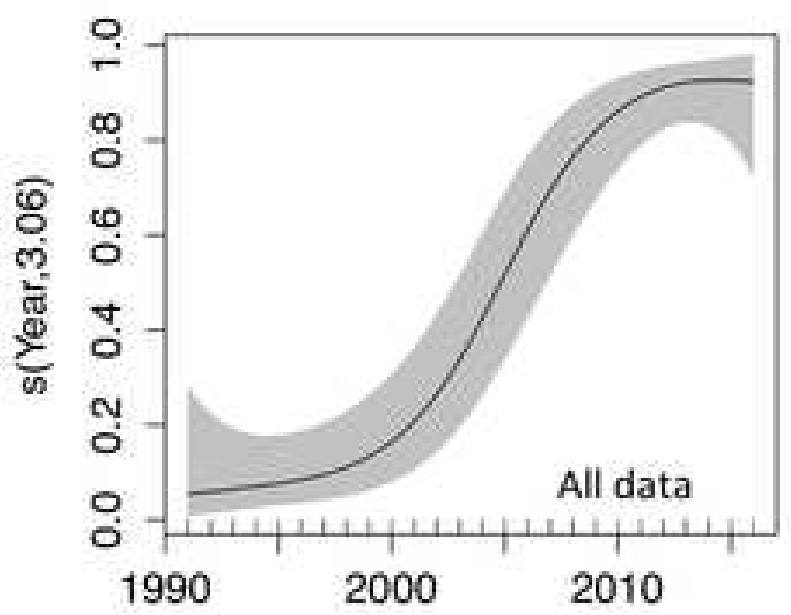

c)
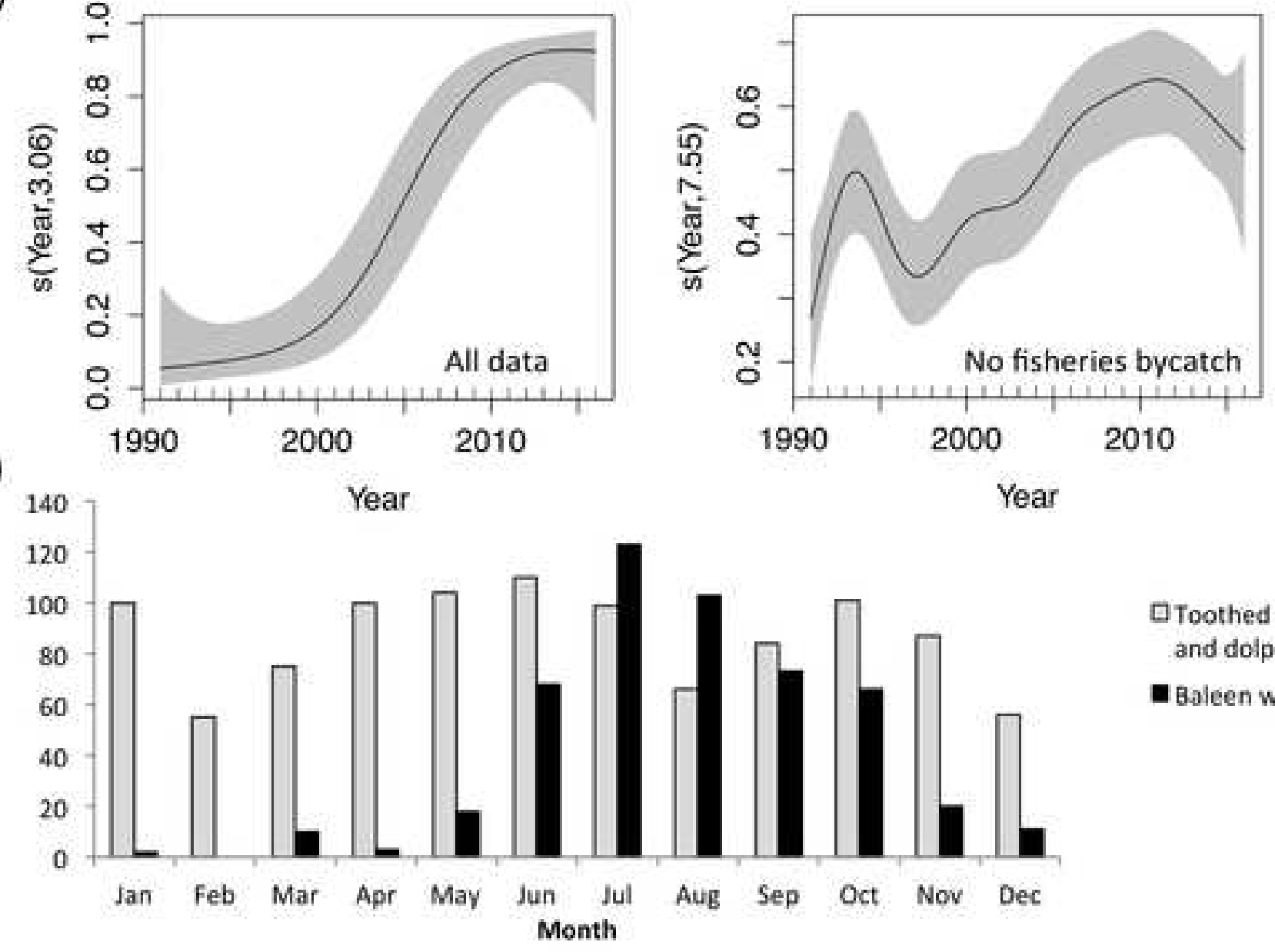

QToothed whales and dolphins

- Baleen whales 
a)

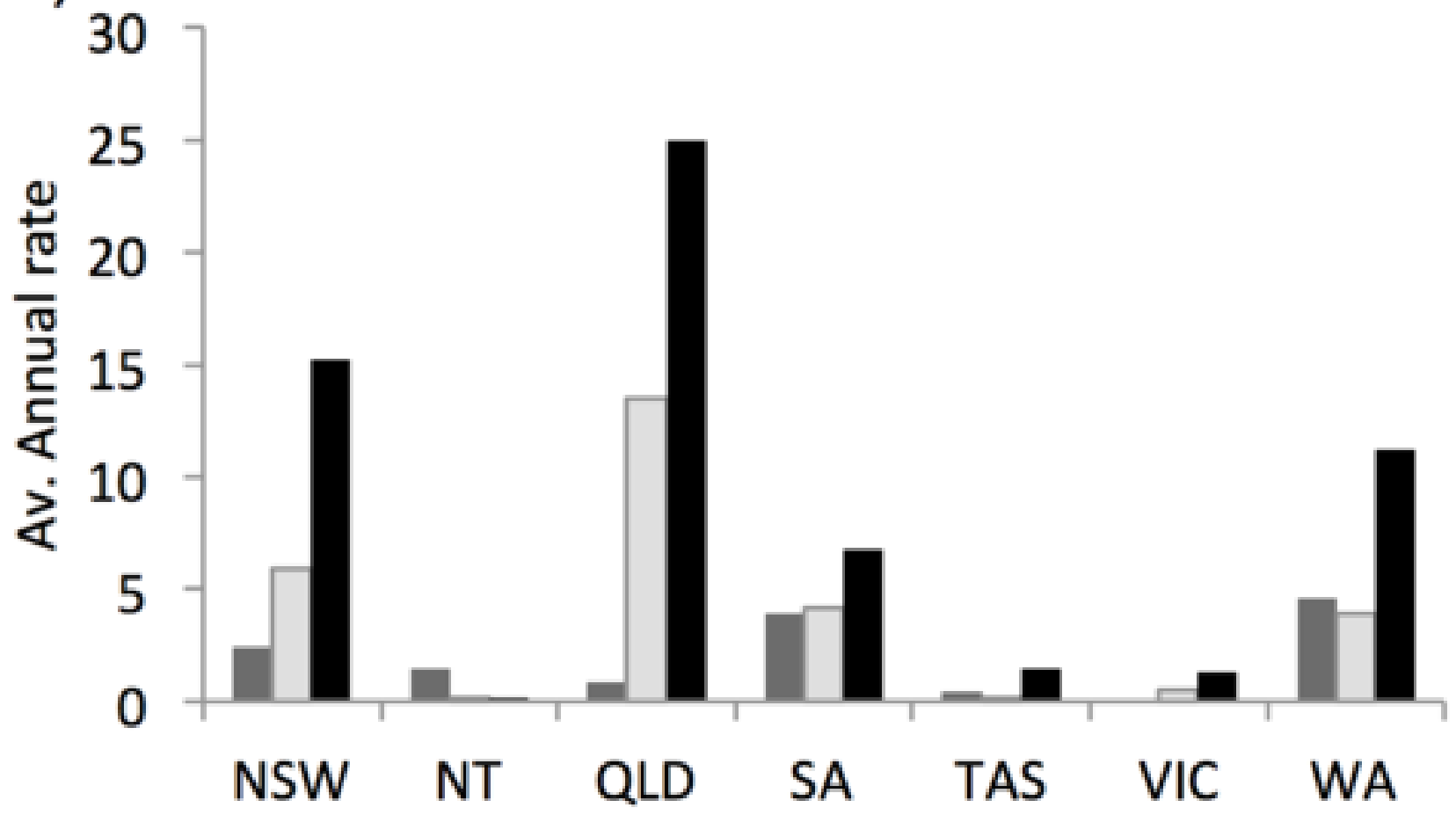

b)

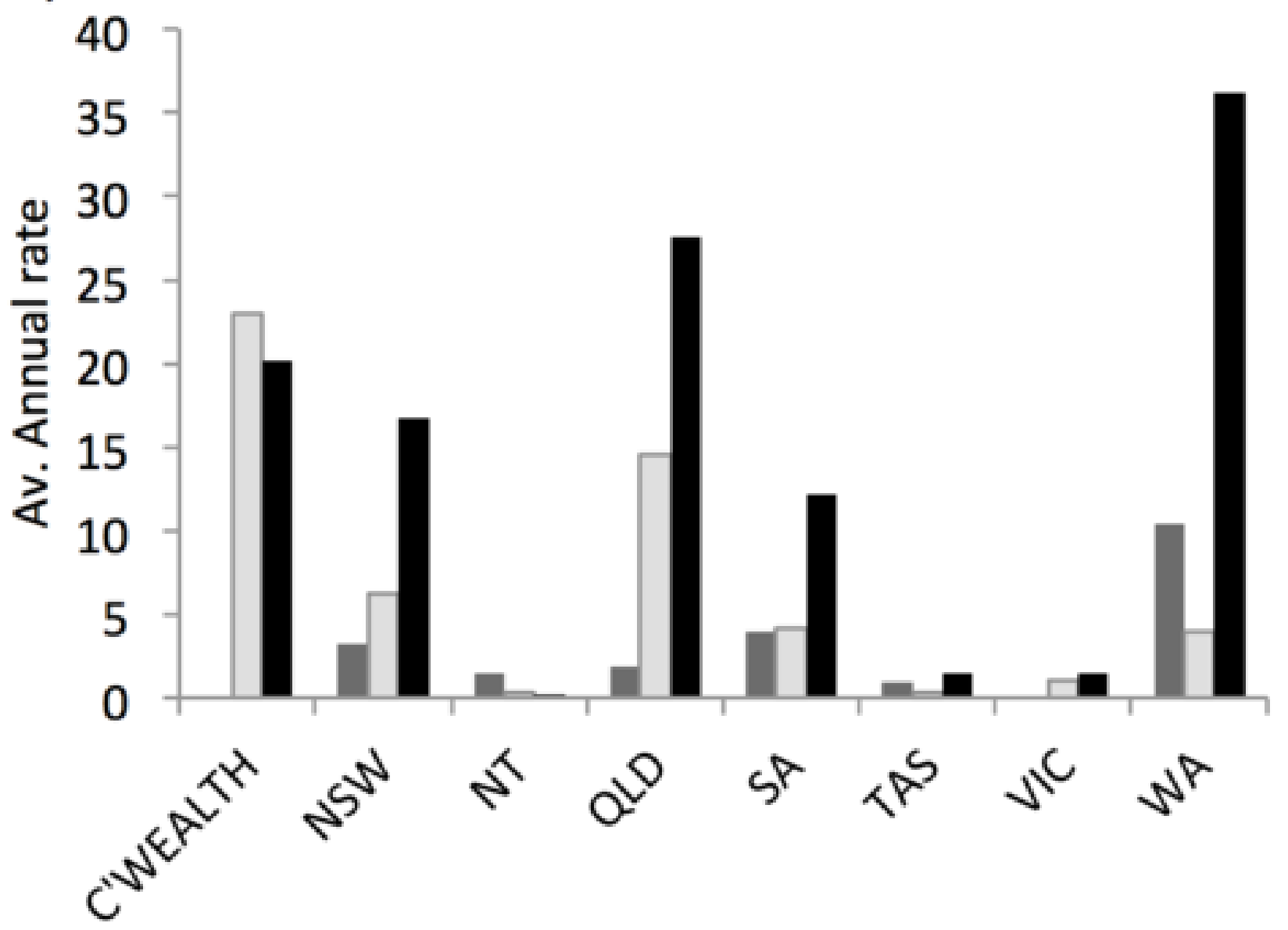




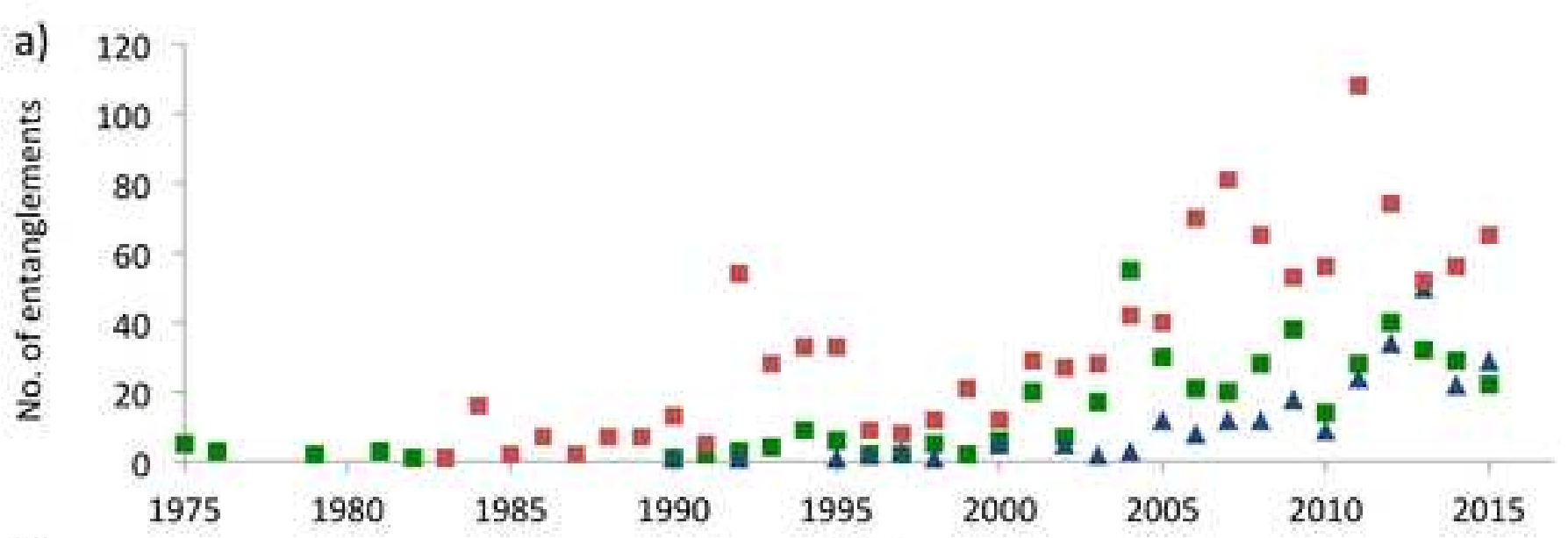

b) Year

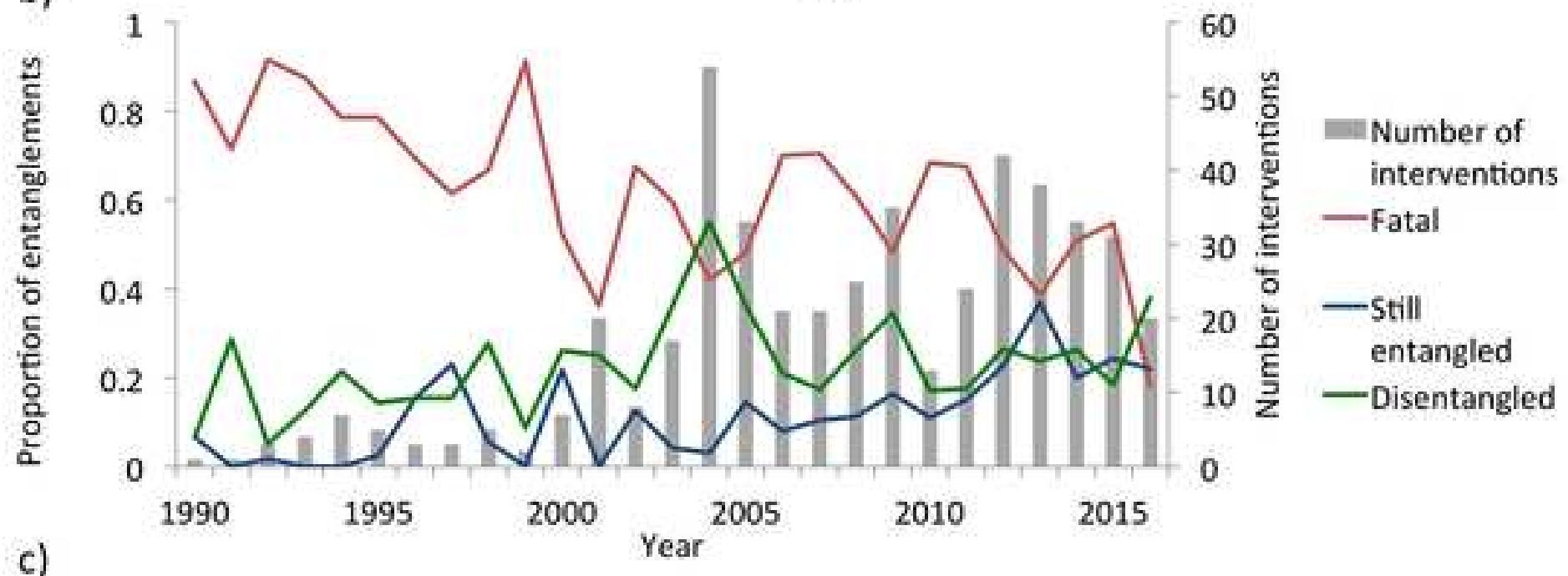

c)

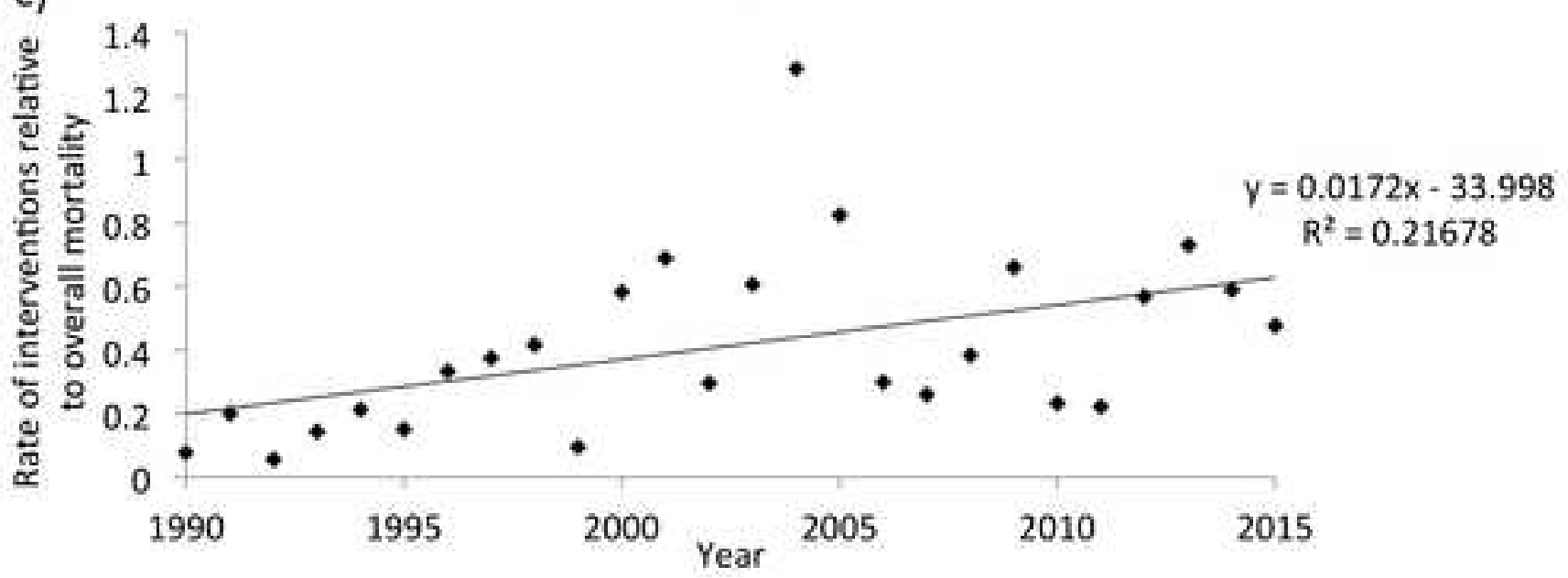




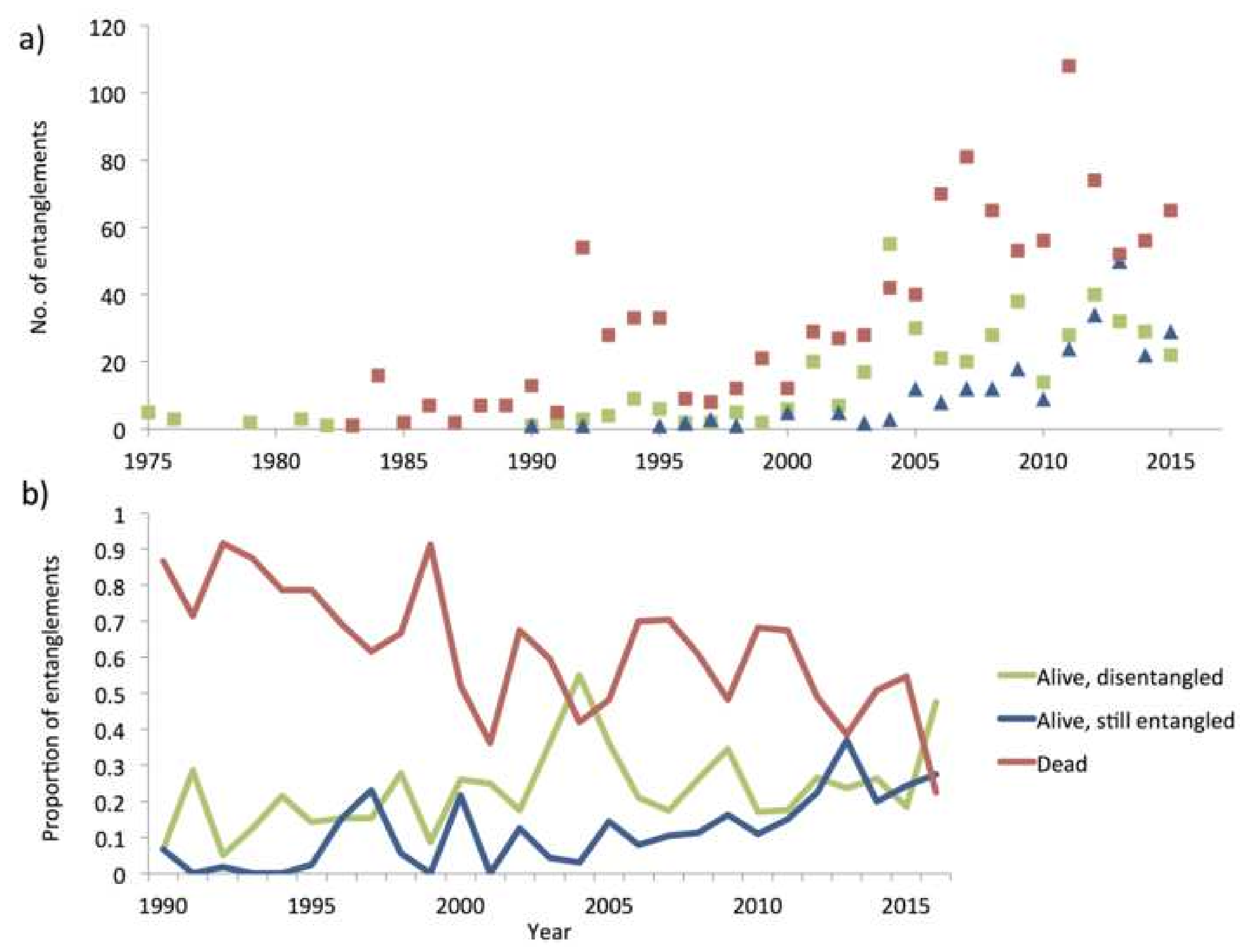

b)

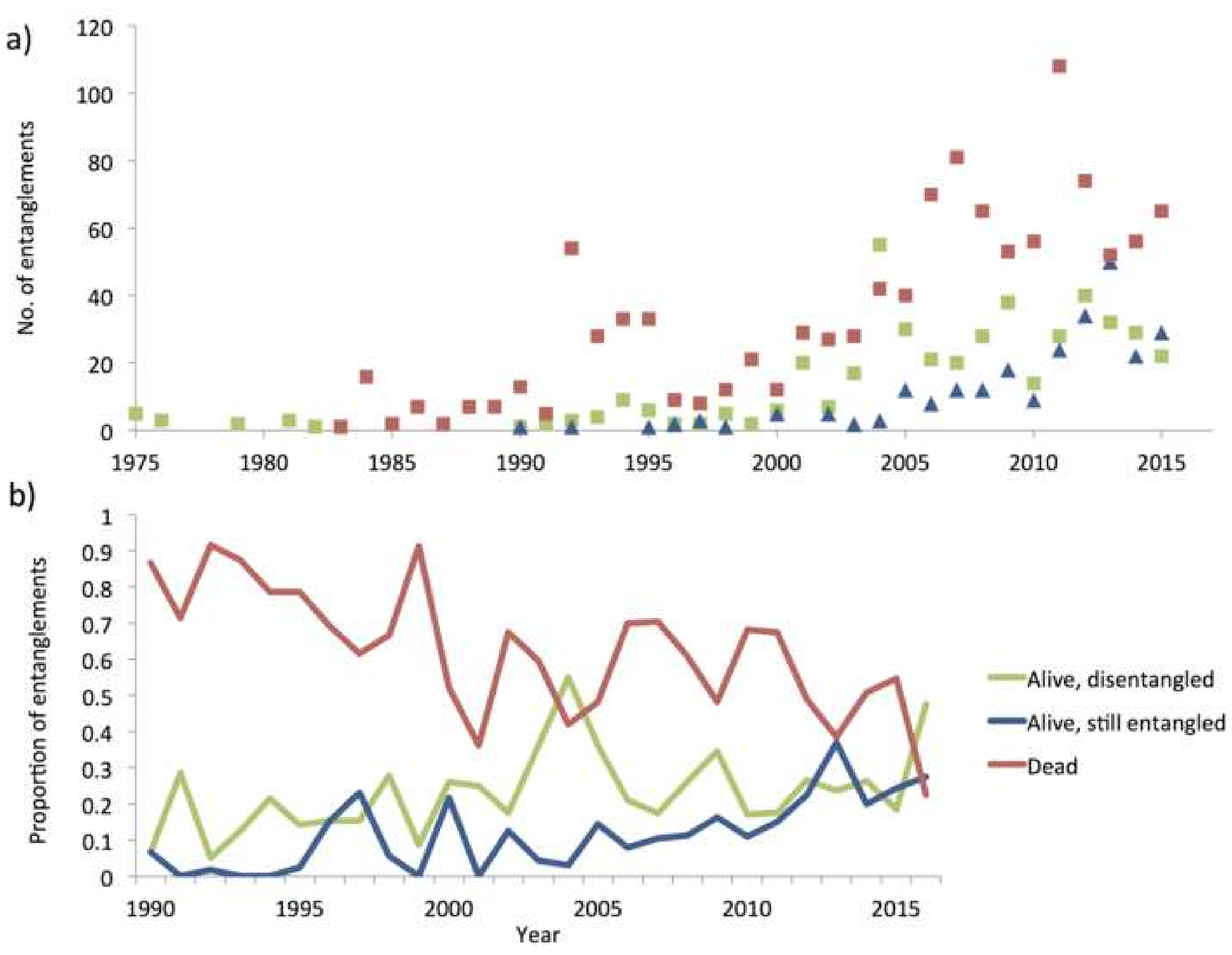




\section{aquaculture} $\square$ Gillnet

$\square$ Line

- Net

$\square$ Non fishing

$\square$ Other

Purse seine

$\square$ Rope

$\square$ Shark control - drumline

$\square$ Shark control - net

Trap

$\square$ Trawl

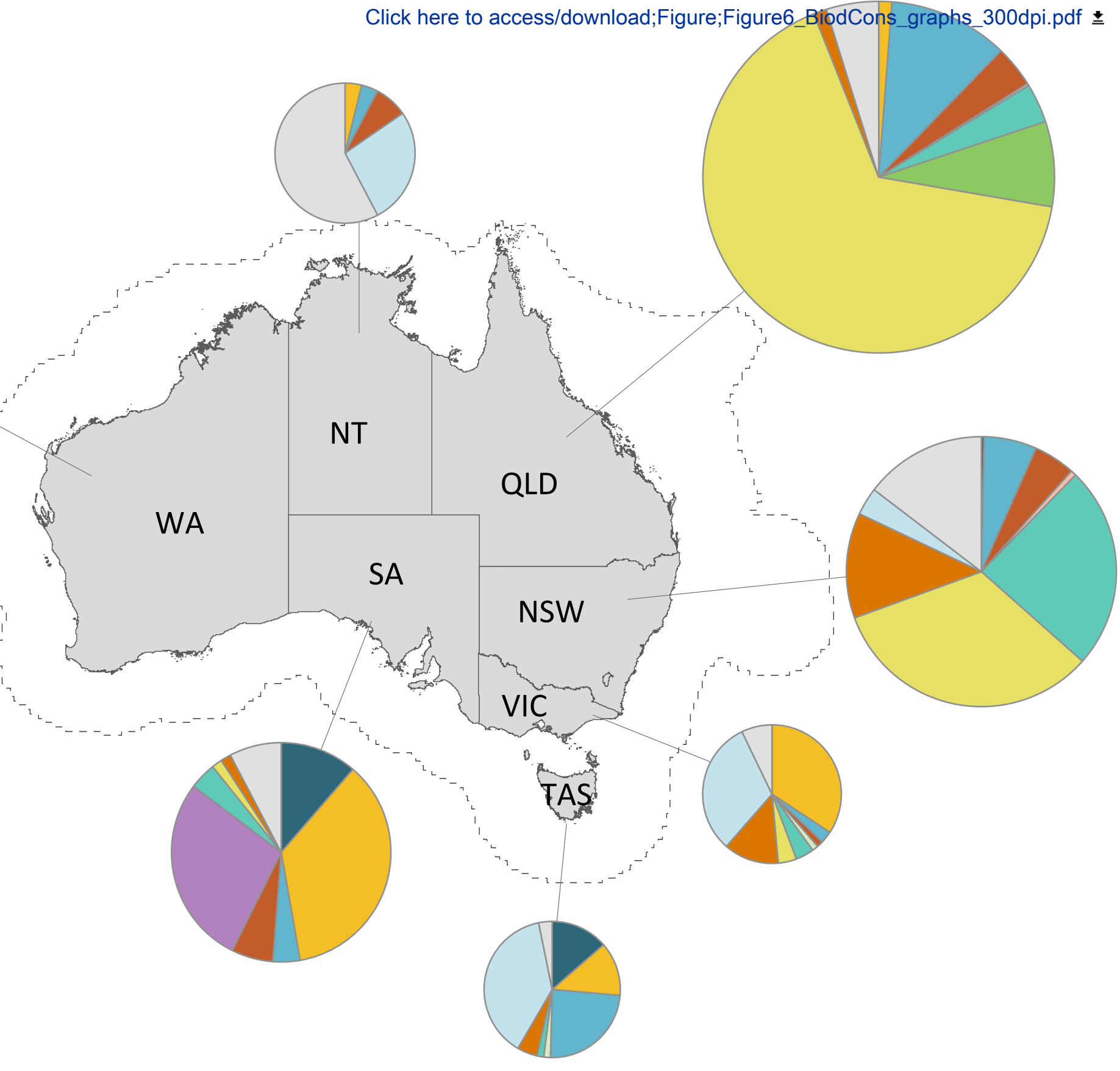

$\square$ Unidentified gear 
Click here to access/download Attachment to Manuscript

BiodCons_Supplementary_Tullochetal_2018_resub_Jun e2019.docx 